\title{
Fast-Onset Long-Term Open-State Block of Sodium Channels by A-type FHFs Mediates Classical Spike Accommodation in Hippocampal Pyramidal Neurons
}

\author{
๑Kumar Venkatesan, ${ }^{1 \star}$ Yue Liu, ${ }^{1,2 *}$ and ${ }^{\circledR}$ Mitchell Goldfarb ${ }^{1}$ \\ ${ }^{1}$ Department of Biological Sciences, Hunter College of City University, New York, New York 10065 and ${ }^{2}$ The Graduate Center Neuroscience Training \\ Subprogram at City University, New York, New York 10016
}

\begin{abstract}
Classical accommodation is a form of spike frequency adaptation in neurons whereby excitatory drive results in action potential output of gradually decreasing frequency. Here we describe an essential molecular component underlying classical accommodation in juvenile mouse hippocampal CA1 pyramidal neurons. A-type isoforms of fibroblast growth factor homologous factors (FHFs) bound to axosomatic voltage-gated sodium channels bear an N-terminal blocking particle that drives some associated channels into a fast-onset, long-term inactivated state. Use-dependent accumulating channel blockade progressively elevates spike voltage threshold and lengthens interspike intervals. The FHF particle only blocks sodium channels from the open state, and mutagenesis studies demonstrate that this particle uses multiple aliphatic and cationic residues to both induce and maintain the long-term inactivated state. The broad expression of A-type FHFs in neurons throughout the vertebrate CNS suggests a widespread role of these sodium channel modulators in the control of neural firing.
\end{abstract}

Key words: A-type FHF; accommodation; hippocampus; long-term inactivation; open-state block; voltage gated sodium channel

\section{Introduction}

Intrinsic excitability, the relationship between a neuron's synaptic inputs and firing outputs, helps define the properties of larger neuronal networks that ultimately govern animal learning and behavior. Spike accommodation, also termed spike-frequency adaptation (Benda and Herz, 2003), is an excitation property of many neurons defined as a decreasing rate of action potential firing during a steady excitatory driving current. In classical accommodation, also described as regular-spiking adaptation, action potentials are continuously generated during the current injection period, but with gradually increasing interspike intervals, while in burst accommodation, an accommodation phase of several spikes is followed by a long period devoid of firing (Gupta et al., 2000; Y. Wang et al., 2004; Aracri et al., 2006; Wozny and Williams, 2011). Spike accommodation has been shown to play roles in perceptual processing and learning (Moyer et al., 2000; Benda et al., 2005; Peron and Gabbiani, 2009).

Received March 28, 2014; revised 0ct. 3, 2014; accepted 0ct. 20, 2014

Author contributions: M.G. designed research; K.V. and Y.L. performed research; K.V. and Y.L. analyzed data;M.G. wrote the paper.

This work was supported by Public Health Service grants R01GM098540 to M.G. and U24NS050606 to University of California Davis/National Institutes of Health (NIH) NeuroMab. We are highly grateful to the UC Davis/NIH NeuroMab Facility for generating monoclonal N235/22 (pan-A-FHF) in response to our request. We thank Jacopo Magistretti and Srdjan Antic for thoughtful comments on this manuscript.

*K.V. and Y.L. contributed equally to this work.

The authors declare no competing financial interests.

Correspondence should be addressed to Mitchell Goldfarb, Department of Biological Sciences, Room HN810, Hunter College, 695 Park Avenue, New York, NY 10065. E-mail: Goldfarb@genectr.hunter.cuny.edu.

DOI:10.1523/JNEUROSCI.1271-14.2014

Copyright $\odot 2014$ the authors $\quad 0270-6474 / 14 / 3416126-14 \$ 15.00 / 0$
Burst-type accommodation is mediated via slowly developing potassium currents derived from both calcium-dependent potassium channels along with M-type voltage-gated potassium channels. The calcium-activated outward potassium current enhances the action potential's slow afterhyperpolarization, initially lengthening interspike intervals and then preventing depolarization to spike threshold (Moyer et al., 1992; Pedarzani and Storm, 1993; Faber and Sah, 2002; Tombaugh et al., 2005). Curiously, this mechanism of burst accommodation becomes more prevalent in CA1 pyramidal neurons of aging animals (Moyer et al., 1992; Tombaugh et al., 2005), but is only uncovered in CA1 neurons from young adults when certain voltage-gated potassium channels are inhibited pharmacologically (Chen et al., 2014). The slow activating and deactivating M-type voltage-gated potassium current is also essential for burst spiking in CA1 pyramidal neurons (Peters et al., 2005).

In contrast, molecular mechanisms underlying classical accommodation are less well understood. Genetic blockade of M-type potassium channels reduces, but does not eliminate, classical accommodation in CA1 pyramidal neurons (Otto et al., 2006). Additionally, slow recovery of sodium channels from the inactivated state has been suggested as contributing to classical accommodation (Martina and Jonas, 1997), and this suggestion has been strengthened through both computational studies (Platkiewicz and Brette, 2011) and dynamic current-clamp experiments (Milescu et al., 2010).

Voltage-gated sodium channels can enter into a prolonged refractory state by two distinct pathways. Slow inactivation is often defined as a transition requiring membrane depolarization 
for one to several seconds and rendering sodium channels refractory to opening over hundreds of milliseconds following membrane repolarization (Ulbricht, 2005). As slow inactivation is mediated by the voltage sensor domains within the channel's pore-forming $\alpha$-subunit (Silva and Goldstein, 2013a,b), this phenomenon can occur in a broad range of excitable cell types (Ulbricht, 2005), although susceptibility to slow inactivation can be modulated by channel phosphorylation (Y. Chen et al., 2006). Slow inactivation of sodium channels is likely responsible for spike frequency adaptation during prolonged multisecond stimulus intervals (Fleidervish et al., 1996).

In contrast, fast-onset long-term inactivation is a distinct process induced within 1-5 ms of depolarization, also resulting in long refractory periods following repolarization. Fast-onset longterm sodium channel inactivation was first described in Myxicola giant axon (Rudy, 1981) and in the somatic and dendritic compartments of hippocampal CA1 pyramidal neurons (Colbert et al., 1997; Jung et al., 1997; Martina and Jonas, 1997). These findings suggested that long-term sodium channel inactivation underlies classical accommodation (Martina and Jonas, 1997) and dendritic spike attenuation (Andreasen and Lambert, 1995; Callaway and Ross, 1995; Colbert et al., 1997; Jung et al., 1997). Long-term sodium channel inactivation has also been described in spinal motor neurons (Miles et al., 2005), medullary raphe neurons (Milescu et al., 2010), and cerebellar nuclear and Purkinje neurons (Aman and Raman, 2007). Several reports have referred to fast-onset long-term inactivation as slow inactivation or accumulating slow inactivation (Rudy, 1981; Mickus et al., 1999; Miles et al., 2005; Aman and Raman, 2007; Milescu et al., 2010), with one study suggesting that slow-onset and accumulating fast-onset slow-recovering inactivation are equivalent sodium channel states arrived at through different pathways (Mickus et al., 1999).

A-type isoforms of fibroblast growth factor homologous factors (FHFs) (Smallwood et al., 1996; Hartung et al., 1997; Q. Wang et al., 2000) have been shown to induce fast-onset sodium channel long-term inactivation upon ectopic coexpression with sodium channels (Rush et al., 2006; Laezza et al., 2009; Dover et al., 2010), although the biological significance of this finding was not established. A-type FHFs bear an N-terminal inactivation particle that competes with a sodium channel's intrinsic fast inactivation mechanism upon membrane depolarization (Dover et al., 2010). Here, we use a novel neutralizing monoclonal antibody to show that A-type FHFs are broadly expressed in neurons within the brain and mediate fast-onset long-term inactivation of a subset of sodium channels within the soma and proximal processes of juvenile mouse hippocampal CA1 pyramidal neurons. During a spike train driven by constant current application, A-type FHF-induced progressive loss of sodium channel availability gradually raises the spike threshold to induce classical accommodation. We further show that the N-terminal particle common to all A-type FHFs employs a set of aliphatic and cationic residues to block open sodium channels and maintain a long-term inactivated state that is distinct from slow inactivation.

\section{Materials and Methods}

Plasmids, mutagenesis, and transfection of Neuro2A cells. TTX-resistant murine $\mathrm{Na}_{\mathrm{v}} 1.6^{\text {TTXr }}\left(\mathrm{Na}_{\mathrm{v}} 1.6_{\mathrm{Y} 371 \mathrm{~S}}\right)$ cDNA in bicistronic vector pIRESneo3 (Clontech) was described previously (Dover et al., 2010). Human $\mathrm{Na}_{\mathrm{v}} 1.5$ cDNA in the pcDNA3.1 expression vector was a gift from R. Kass. Fast inactivation-defective channels $\mathrm{Na}_{\mathrm{v}} 1.6_{\mathrm{F} 1478 \mathrm{Q}}^{\mathrm{TTXr}}$ and $\mathrm{Na}_{\mathrm{v}} 1.5_{\mathrm{F} 1486 \mathrm{Q}}$ bearing Phe $\rightarrow$ Gln substitution in their respective DIII/IV loops (West et al., 1992; Eaholtz et al., 1999; G.K. Wang et al., 2006; Dover et al., 2010) were generated with complementary mutagenic primers and PfuTurbo DNA polymerase (Stratagene). Bicistronic expression of FHF and GFP in pIRES2-ZsGreen1 (Clontech) was described previously (Dover et al., 2010). FHF2A mutations I5A, L9A, I10A, R11Q, K13Q, R14Q, R17Q, $\mathrm{R} 11 \mathrm{Q} / \mathrm{R} 14 \mathrm{Q}, \mathrm{R} 11 \mathrm{Q} / \mathrm{R} 17 \mathrm{Q}$, and R14Q/R17Q were generated using complementary mutagenic primers.

Neuro2A cells were used for expression of sodium channels and FHFs by Lipofectamine (LFN2000)-mediated plasmid transfection (Lou et al., 2005; Dover et al., 2010) at a 2:1 ratio of $\mathrm{Na}_{\mathrm{v}}$ - and FHF-expressing plasmids. For protein expression analysis, transfected cells were lysed after $24 \mathrm{~h}$ culture. For electrophysiology, transfected cells were trypsinized, plated onto coverslips, and maintained for $24-48 \mathrm{~h}$ before transfer to the recording chamber.

Peptides, antibodies, immunoblots, and immunofluorescence. N-terminally acetylated peptide corresponding to FHF2A residues 2-18 (F2A 2-18$_{2}$; acetylAAAIASSLIRQKRQARE) and unmodified peptide corresponding to $\mathrm{Na}_{\mathrm{v}} \beta 4$ residues $154-167$ ( $\beta 4_{154-167}$; KKLITFILKKTREK) were custom synthesized, purified by HPLC, and confirmed by mass spectroscopy (China Peptides). Mouse monoclonal N235/22 ( $\left.\mathrm{IgG}_{2 \mathrm{~b}}\right)$ was generated against peptide $\mathrm{F}_{2} \mathrm{~A}_{2-18}$ in collaboration with the University of California (UC) Davis/NIH NeuroMab Facility. Other antibodies included rabbit anti-FHF2(C terminus; Schoorlemmer and Goldfarb, 2002), mouse monoclonal ( $\operatorname{IgG}_{1}$ ) anti-ankyrin G (Santa Cruz Biotechnology), and mouse monoclonal N126B/31 ( $\left.\operatorname{IgG}_{2 \mathrm{~b}}\right)$ anti-neuregulin extracellular domain (UC Davis/NIH NeuroMab Facility). Horseradish peroxidaseconjugated secondary antibodies were from Jackson ImmunoResearch, and fluorescent secondary antibodies along with TOPRO iodide were from Invitrogen.

Cell lysates in 1\% Triton X-100 were electrophoresed through 4-20\% precast polyacrylamide SDS gels (Pierce Thermo Fisher), electrotransferred to PVDF membrane, blocked in 5\% milk, and probed with primary and peroxidase-conjugated secondary antibodies that were detected with chemiluminescent substrate and autoradiography. For immunofluorescence, $4 \%$ paraformaldehyde-fixed brain $20 \mu \mathrm{m}$ cryosections or $200 \mu \mathrm{m}$ vibratome brain slices fixed after electrophysiological recordings were permeabilized in $0.5 \%$ Triton X-100, blocked with $10 \%$ horse serum, and probed with primary and fluorescent secondary antibodies. Sections were briefly stained with TOPRO iodide just before mounting and confocal microscopy (Leica Instruments).

Sodium current measurements in transfected Neuro2A cells. For analysis of $\mathrm{Na}_{\mathrm{v}} 1.6^{\text {TTXr}}$-mediated inward sodium currents, $\mathrm{O}_{2}: \mathrm{CO}_{2}(95: 5$; carbogen)-bubbled extracellular solution contained the following (in mM): $109 \mathrm{NaCl}, 26 \mathrm{NaHCO}_{3}, 10$ HEPES, $4.7 \mathrm{KCl}, 11$ glucose, $1.2 \mathrm{MgCl}_{2}$, $2 \mathrm{CaCl}_{2}, 0.2 \mathrm{CdCl}_{2}, 3$ myo-inositol, $2 \mathrm{Na}$ pyruvate, 0.001 TTX (buffered to $\mathrm{pH} 7.2$ with $\mathrm{NaOH}$ ), and the intracellular pipette solution (Pipette Solution I) contained $104 \mathrm{CsF}, 50$ tetraethylamine chloride (TEA), 10 HEPES, 5 glucose, $2 \mathrm{MgCl}_{2}, 10$ EGTA, and $2 \mathrm{Na}_{2} \mathrm{ATP}, 0.2 \mathrm{Mg}$-GTP (buffered to $\mathrm{pH} 7.2$ with $\mathrm{CsOH}$ ). For analysis of $\mathrm{Na}_{\mathrm{v}} 1.5$-mediated sodium currents, solutions were modified to lower the sodium ion reversal potential; extracellular $\mathrm{NaCl}$ was reduced from 109 to 29 and replaced with 80 choline chloride, and pipette solution was changed to $100 \mathrm{NaF}$, $20 \mathrm{NaCl}, 30$ TEA, 10 HEPES, 5 glucose, $2 \mathrm{MgCl}_{2}, 10$ EGTA, $2 \mathrm{Na}_{2} \mathrm{ATP}$, and $0.2 \mathrm{NaGTP}$ (buffered to $\mathrm{pH} 7.2$ with $\mathrm{NaOH}$; Pipette Solution II). When peptides $(1 \mathrm{~mm})$ or antibodies $(500 \mu \mathrm{g} / \mathrm{ml})$ were used, pipettes were backfilled $\sim 0.5 \mathrm{~mm}$ with polypeptide-free solution before topfilling with peptide-containing or antibody-containing solution. The recording chamber was set within a Nikon EF600 microscope equipped with $40 \times$ water-immersion objective and video camera. Transfected cells were identified by green fluorescence and whole-cell configuration was induced after achieving a 5-20 G $\Omega$ seal. For experiments using pipettes with peptides, antibodies, and their negative controls, series resistance after break-in was 7-14 M $\Omega$. For experiments testing FHF mutagenesis that did not use peptide/antibody perfusion, wider pipette tips were used yielding a series resistance of $2.5-5 \mathrm{M} \Omega$.

Voltage-clamp and current recording was conducted using an Axopatch 200B amplifier, Digidata 1322 digital/analog interface, and pCLAMP9 software (Molecular Devices). When using patch pipettes containing peptides, recordings were initiated after a 10 min perfusion period, while for patch pipettes containing antibody, recordings were 
conducted 2 min after gaining cell access (preperfusion control) and at later time periods after antibody perfusion. Recording signals were filtered at $5 \mathrm{kHz}$ and digitized at $10 \mathrm{kHz}$ or $20 \mathrm{kHz}$. Membrane capacitance and series/access resistance were calculated from current responses to a voltage-clamped step depolarization from -90 to $-60 \mathrm{mV}$. For measurements of evoked sodium currents, capacitive and leak currents were subtracted during data acquisition using the presweep hyperpolarizing $\mathrm{P} / \mathrm{N}$ method in the pCLAMP9 software.

Protocols for measuring voltage dependence of sodium channel activation and steady-state inactivation and accumulation into and recovery from long-term inactivation were described previously (Dover et al., 2010). Each sweep of the three-step protocol for measurement of longterm inactivation voltage dependence (Fig. $7 A, B$ ) consisted of a first depolarization at variable voltage to assay for channel activation, a $40 \mathrm{~ms}$ $-90 \mathrm{mV}$ recovery phase, and a second depolarization to $0 \mathrm{mV}$ to measure available channels and thereby assay for long-term inactivation. The protocol has been modified from its previous description (Dover et al., 2010) by shortening the duration of the first depolarization in each sweep to 5 ms. Longer duration of the first depolarization left shifts the apparent voltage dependence of long-term inactivation, since long-term inactivation is a stable state that continually captures channels undergoing reversible open/close transitions; for example, a voltage that gives $10 \%$ maximal channel activation enables a greater percentage of channels to traverse the open state over a longer duration of depolarization, allowing for greater long-term inactivation from the open state. Second, voltage dependence of channel activation and long-term inactivation was assayed on $\mathrm{Na}_{\mathrm{v}} 1.6_{\mathrm{F} 1478 \mathrm{Q}}$, as fast inactivation distorts measurement of actual voltage dependence of other channel states (Gonoi and Hille, 1987). Mutual competition for channel block between FHF2A- and $\mathrm{Na}_{\mathrm{v}} \beta 4$-derived peptides were assayed on cells expressing $\mathrm{Na}_{\mathrm{v}} 1.5_{\mathrm{F} 1486 \mathrm{Q}}$ (Fig. $7 \mathrm{C}-\mathrm{H}$ ), as ectopically expressed $\mathrm{Na}_{\mathrm{v}} 1.6$ does not readily show $\mathrm{Na}_{\mathrm{v}} \beta 4$-induced resurgent current (Y. Chen et al., 2008). In these experiments, sodium ion concentrations in solutions were modified to adjust the sodium reversal potential to approximately $-10 \mathrm{mV}$ and a protocol of four depolarization cycles to $70 \mathrm{mV}$ separated by $40 \mathrm{~ms}$ recovery periods at $-100 \mathrm{mV}$.

Recordings in mouse hippocampal CA1 pyramidal neurons. 129S2/ SvPasCrl mice of either sex (P14-P25) were killed by decapitation after isoflurane anesthesia, and transverse 100-300 $\mu \mathrm{m}$ hippocampal slices were cut with a Leica VT1200S (Leica Microsystems) in ice-cold aCSF containing the following (in $\mathrm{mM}$ ): $126 \mathrm{NaCl}, 3 \mathrm{KCl}, 2.5 \mathrm{CaCl}_{2}, 1 \mathrm{MgCl}_{2}$, $1.25 \mathrm{NaH}_{2} \mathrm{PO}_{4}, 26 \mathrm{NaHCO}_{3}$, and 10 D-glucose, 300-305 mOsm/L, pH $7.3-7.4$, when bubbled with carbogen. Slices were immediately placed in a $36^{\circ} \mathrm{C}$ holding chamber containing carbogenated aCSF and were allowed to recover for a minimum of $30 \mathrm{~min}$ before transfer to the roomtemperature recording chamber.

For sodium current analysis, the carbogen-bubbled extracellular solution contained the following (in mM): $100 \mathrm{NaCl}, 26 \mathrm{NaHCO}_{3}, 19.5$ TEA, 4-AP), $3 \mathrm{KCl}, 10$ glucose, $2 \mathrm{MgCl}_{2}, 2 \mathrm{CaCl}_{2}, 2 \mathrm{BaCl}_{2}$, and $0.5 \mathrm{CdCl}_{2}$, and patch pipettes were filled with Pipette Solution I. For calcium current analysis, the extracellular solution above was modified by omitting $\mathrm{CdCl}_{2}$ and adding $1 \mu \mathrm{M}$ TTX. For potassium current analysis, extracellular solution was aCSF supplemented with $0.5 \mathrm{mM} \mathrm{CdCl}_{2}$ and $1 \mu \mathrm{M}$ TTX, and intracellular pipette solution (Pipette Solution II) contained 125 K-gluconate, $10 \mathrm{KCl}, 5 \mathrm{HEPES}, 4 \mathrm{NaCl}, 0.1 \mathrm{CaCl}_{2}, 2 \mathrm{MgCl}_{2}, 4 \mathrm{MgATP}$, and $0.3 \mathrm{NaGTP}$, adjusted to $\mathrm{pH} 7.3$ with $\mathrm{KOH}$ (Pipette Solution III). For action potential firing analysis, aCSF served as external solution and Pipette Solution III was used in pipettes. When antibodies $(500 \mu \mathrm{g} / \mathrm{ml})$ were used, pipettes were backfilled $\sim 0.5 \mathrm{~mm}$ with polypeptide-free solution before top-filling with antibody-containing solution. The recording chamber was set within a Nikon Eclipse FN1 microscope equipped with $63 \times$ water-immersion objective and video camera. Hippocampal CA1 neuron soma were visualized with infrared light and differentiation interference contrast optics, pipette seals of 5-10 G $\Omega$ achieved, and whole-cell access yielded series resistance of 6-12 M $\Omega$ for Pipette Solution I and II or 12-25 $\mathrm{M} \Omega$ for Pipette Solution III.

Voltage-clamp and current-clamp experiments were conducted using a MultiClamp700 amplifier, Digidata 1440A digital/analog interface, and pCLAMP10 software (Molecular Devices). When using patch pipettes containing antibody, recordings were conducted $5 \mathrm{~min}$ after gaining cell access (preperfusion control) and at later time periods after antibody perfusion. After the perfusion of cells, some pipettes were pulled back during suction application to isolate a nucleated patch and then rerecorded. Recording signals were filtered at $5 \mathrm{kHz}$ and digitized at $10 \mathrm{kHz}$ or $20 \mathrm{kHz}$. Membrane capacitance and series/access resistance were calculated from current responses to a voltage-clamped hyperpolarization step. For measurements of evoked sodium currents, capacitive and leak currents were subtracted using the presweep hyperpolarizing $\mathrm{P} / \mathrm{N}$ method in the pCLAMP10 software. For recording action potentials, the cell's holding potential was adjusted to approximately $-70 \mathrm{mV}$ in current-clamp mode and then subjected to $800 \mathrm{~ms}$ current injection sweeps in $20 \mathrm{pA}$ steps while applying bridge balance correction. In some cells, goat anti-rat IgG Oregon Green conjugate $(500 \mu \mathrm{g} / \mathrm{ml})$ was included in the pipette, and after $30 \mathrm{~min}$ recording, the pipette was gently pulled off, and the slice was fixed and processed for ankyrin $\mathrm{G}$ immunofluorescence to assay the diffusion of Ig through dendritic and axonal processes.

Spike data analysis. Capacitance (C) and charging decay time (Tau) in recorded neurons was calculated from the current transient induced by a voltage-clamp step, and series resistance was calculated as $R_{\text {series }}=$ Tau/C. Input resistance $\left(R_{\text {input }}\right)$ was measured by the ohmic voltage/ current relationship. Spiking profiles in hippocampal neurons were only considered for cells showing $<20 \% R_{\text {series }}$ and $R_{\text {input }}$ deviation over the entire recording period. Each spike interval was plotted against the spike number, beginning with the third spike interval (as some neurons displayed an initial burst doublet or triplet; Fig. $3 A-H$ ). Spikes were analyzed from a current sweep yielding a third spike interval of 40-55 ms. Greater than $80 \%$ of neurons displayed spike accommodation 5 min after achieving whole-cell access, as assessed by highly significant deviation from a set of hypothetical nonaccommodating intervals of $50 \pm 5 \mathrm{~ms}$ ( $p<0.001$ by ANCOVA). ANCOVA calculations were performed using an on-line calculator (http://vassarstats.net). To assess stability of accommodation during pipette perfusion, spike intervals $\geq 3$ and with third spike interval of $40-55 \mathrm{~ms}$ were compared at 5 min versus $50 \mathrm{~min}$ post access, and trendlines were assessed for significant difference if $p<$ 0.05 by ANCOVA. After ascribing significant or insignificant change in accommodation for each neuron in different treatment groups, the overall statistical significance of a particular treatment was assessed by $\chi^{2}$ analysis using an on-line calculator (http://vassarstats.net). Spike voltage threshold was defined as the voltage onset of positive $\delta^{2} \mathrm{~V} / \delta \mathrm{t}^{2}$, calculated using Clampfit10 software (Molecular Devices).

Voltage-gated sodium current data analysis. The percentage of channels in the long-term inactivated state at each depolarization cycle or the percentage of resurgent current at each repolarization under a specific set of conditions (plasmids transfected, peptides or antibodies in pipette, postaccess recording time) were expressed and graphed as mean $\pm \mathrm{SE}$, and the statistical significance of varying one of these conditions (e.g., postaccess recording time) was calculated by the two-tailed Student's $t$ test. For each cell analyzed for voltage dependence of activation, steadystate (fast) inactivation, and long-term inactivation, data at all tested voltages were fit to a Boltzmann equation to establish $\mathrm{V}_{1 / 2}$ and slope $k$ values using Clampfit10, and the values for all cells recorded under the same conditions were expressed and graphed as mean \pm SE. Recovery of channels from long-term inactivation was fitted to a single-term exponential decay equation using Clampfit. Experiments that compared sodium currents before and after antibody perfusion only considered for analysis cells showing $<20 \% R_{\text {series }}$ deviation over the entire recording period.

Voltage-gated calcium current data analysis. Recordings were made 20 min after CA1 neuron access and inward calcium currents were evoked by a $200 \mathrm{~ms}$ depolarization from -90 to $0 \mathrm{mV}$. The amplitude of the persistent current and the amplitude, time-to-peak, and first-order decay of the transient current were assessed using Clampfit. For each of these parameters, values obtained in control cells and those perfused with A-type FHF monoclonal antibody were evaluated by $t$ test for significant difference.

Voltage-gated potassium current data analysis. Recordings were made 20 min after CA1 neuron access and outward potassium currents were evoked by $40 \mathrm{~ms}$ depolarization from $-90 \mathrm{mV}$ to between -30 and 0 


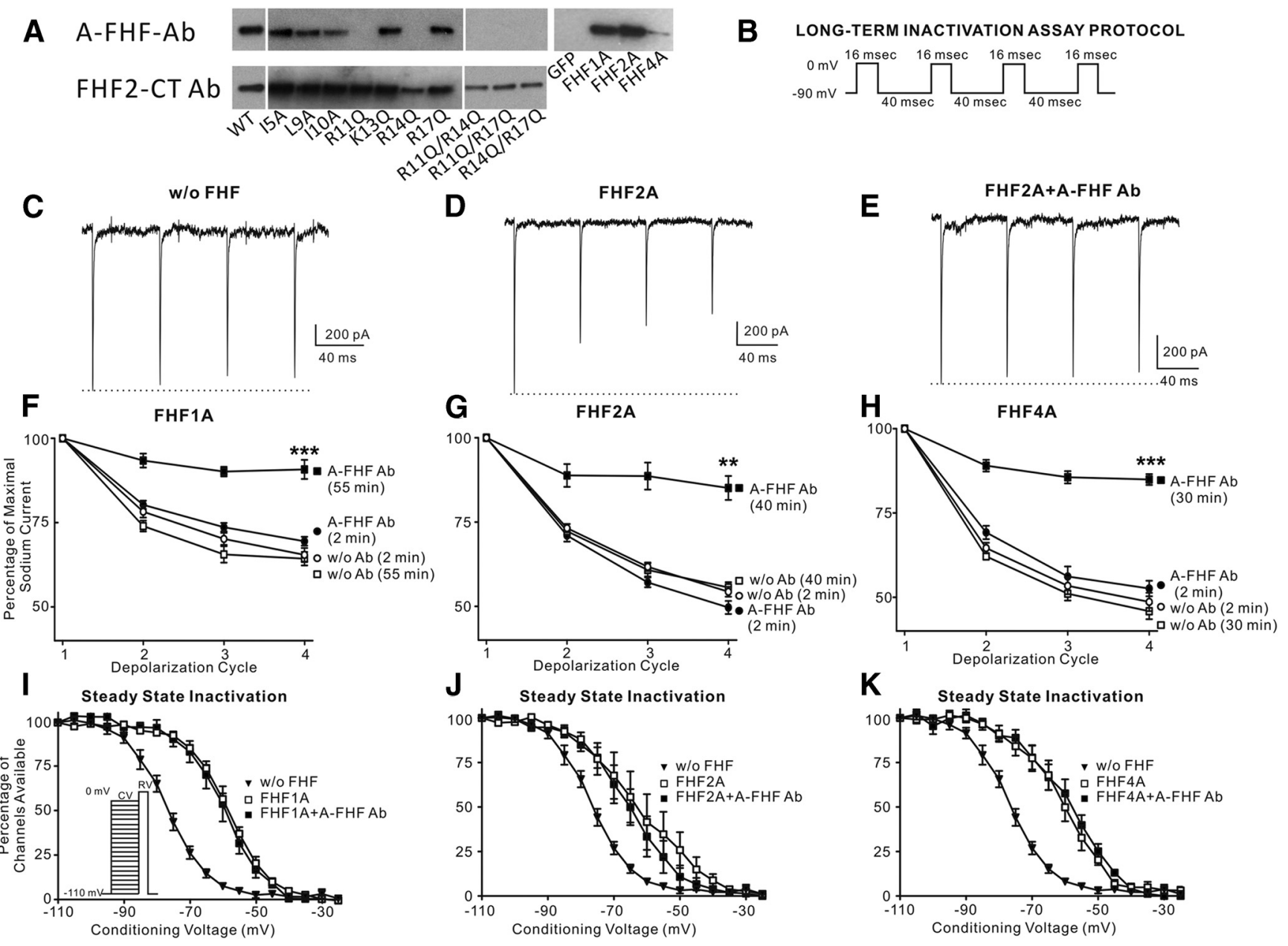

Figure 1. Functional characterization of A-type FHF monoclonal antibody. A, Epitope mapping within the N-terminal domain conserved among A-type FHFs. Neuro2A cells were transfected with vectors expressing different A-type FHFs and mutant derivatives of FHF2A. Lysates were electrophoresed on duplicate gels and immunoblotted with either A-FHF-specific or C terminus-specific FHF2 antibodies (FHF2CT). N235/22 pan-A-FHF reactivity is apparent with a binding epitope that includes residues Arg11 and Arg14. B, Voltage-clamp protocol for accumulating long-term inactivation used in $\mathbf{C}-\boldsymbol{H}$. The $40 \mathrm{~ms}$ intervals at $-90 \mathrm{mV}$ allow for full recovery from fast inactivation, but only partial recovery from long-term inactivation, which has a far slower recovery rate. $\mathbf{C}-\boldsymbol{E}$, TTX-resistant $\mathrm{Na}_{\mathrm{v}} 1.6$ sodium current traces in Neuro2A cells expressing Nav $1.6^{\mathrm{TTX} r}$ only $(\boldsymbol{C})$ or together with FHF2A $(\boldsymbol{D}, \boldsymbol{E})$. $\boldsymbol{E}$, The patch pipette contained A-FHF antibody that was perfused into the cell 40 min before recording. $\boldsymbol{F}-\boldsymbol{H}, \mathrm{A}$-FHF antibody blocks long-term inactivation by any A-type FHF. Graphical display of $\mathrm{Na}_{v} 1.6^{\mathrm{TXX}}$ transient currents from cells expressing FHF1A $(\boldsymbol{F})$, FHF2A (G), or FHF4A $(\boldsymbol{H})$ recorded at $2 \mathrm{~min}$ or longer time periods after cell break-in using pipette solutions with or without A-FHF antibody. Long-term inactivation by each FHF is stable over entire recording period in absence of antibody, but is inhibited when sufficient time is allowed for antibody perfusion ( ${ }^{* *} p<0.002$; ${ }^{* *} p<0.001 ; n=5$ or 6 cells for each test condition). $I-K$, Effect of A-FHF antibody on A-type FHF-induced depolarizing shifts in steady-state $\mathrm{Na}_{\mathrm{v}} \mathrm{I} .6$ inactivation. Noninactivated channel currents were measured at the $0 \mathrm{mV}$ reporting voltage (RV in $I$ inset) following 60 ms hold at various conditioning voltages (CV in Iinset). All A-FHFs induce an $\sim 15 \mathrm{mV}$ depolarizing shift in voltage dependence of $\mathrm{Na}_{\mathrm{v}} 1.6$ steady-state inactivation (Dover et al., 2010). N235/22 A-FHF monoclonal antibody has no effect on steady-state inactivation modulation by FHF1A $(\boldsymbol{I})$, FHF2A $(\boldsymbol{J})$, or FHF4A $(\boldsymbol{K})(n=5$ to 8 cells for each test condition).

$\mathrm{mV}$. Transient currents were highly variable among recorded cells (Fig. $6 G, J)$, precluding quantitative analysis. Persistent potassium currents in control cells and those perfused with A-type FHF monoclonal antibody were evaluated by $t$ test for significant difference.

\section{Results}

Monoclonal antibody to A-type FHFs neutralizes their sodium channel inactivation particles

Each of four FHF genes encodes multiple protein isoforms differing in their $\mathrm{N}$-terminal extensions through alternative sites of transcription initiation and pre-mRNA splicing (Hartung et al., 1997; Munoz-Sanjuan et al., 1999; Q. Wang et al., 2000). The highly conserved $\beta$-trefoil core common to all FHF isoforms binds to the $\mathrm{C}$-terminal cytoplasmic tail of voltage-gated sodium channels (Goetz et al., 2009; C. Wang et al., 2012). The A-type isoforms encoded by all four FHF genes bear $78-100 \%$ pairwise identity through residues $1-18$, and this conserved $\mathrm{N}$ terminus serves as a long-term inactivation particle for voltage-gated so- dium channels by competing with the fast inactivation gating mechanism intrinsic to all sodium channels (Dover et al., 2010).

A monoclonal antibody raised against a peptide corresponding to the predicted $\mathrm{N}$ terminus of FHF2A (NeuroMab N235/22) could be shown to react with FHF1A, FHF2A, and FHF4A proteins (Fig. 1A). The reactive epitope includes residues Arg- 11 and Arg-14 common to all four of the A-type FHFs (Fig. 1A). To test whether Mab N235/22 neutralizes the long-term inactivation particles on A-type FHFs, Neuro2A cells were transfected with vectors to express different A-type FHFs along with a TTXresistant variant of sodium channel $\mathrm{Na}_{\mathrm{v}} 1.6$ (Dover et al., 2010). Transfected cells were patched in the whole-cell configuration and recorded in the presence of TTX, $\mathrm{Cd}^{+2}$, and TEA to isolate inward $\mathrm{Na}_{\mathrm{v}} 1$.6-derived sodium currents using a four-cycle depolarization protocol to detect long-term channel inactivation (Fig. $1 B)$. In some cases, patch pipettes contained $500 \mu \mathrm{g} / \mathrm{ml} \mathrm{Mab}$ $\mathrm{N} 235 / 22$ and cells were recorded at $2 \mathrm{~min}$ after cell break-in be- 
fore substantial intracellular antibody perfusion could occur and again after 30-55 min of antibody perfusion. As described previously, in the absence of FHFs, $\mathrm{Na}_{\mathrm{v}} 1.6$ channels open and fast inactivate upon membrane depolarization, and nearly all channels recover from inactivation within $40 \mathrm{~ms}$ of repolarization and are available to open again upon subsequent depolarizations (Fig. $1 C$ ). In the presence of FHF1A, FHF2A, or FHF4A, a fraction of the channels undergoes longterm inactivation and fails to recover within $40 \mathrm{~ms}$ while the remainder undergoes fast inactivation, leaving progressively fewer channels available to generate sodium current with each successive depolarization (Fig. $1 D, F-H$ ). With Mab $\mathrm{N} 235 / 22$ in the pipette, long-term inactivation mediated by any of the FHFs was largely suppressed after 30-55 min of perfusion (Fig. $1 E-H$ ). The antibody specifically suppressed channel longterm inactivation with no significant effect on the voltage dependence of channel fast inactivation (Fig. $1 I-K$ ), an independent modulatory property of FHFs mediated by regions away from the $\mathrm{N}$ termini of these proteins (Goldfarb et al., 2007; Dover et al., 2010). These data establish Mab N235/22 as a broadly acting and functionally specific inhibitor of A-type FHF-mediated sodium channel longterm inactivation.

\section{A-type FHFs are required for spike accommodation in hippocampal \\ CA1 neurons}

Many classes of vertebrate neurons experience classical spike accommodation (Sawczuk et al., 1995; Faber and Sah, 2002; Y. Wang et al., 2004; Miles et al., 2005; Tombaugh et al., 2005; Chevaleyre and Siegelbaum, 2010; S. Chen et al., 2014). To explore whether A-type FHFs are candidate mediators of accommodation, we surveyed A-type FHF expression in the brain by immunofluorescence. A-type FHFs were readily detectable on neuronal axon initial segments, where they colocalized with ankyrin G (Fig. 2). Expression sites include hippocampal pyramidal layer (Fig. $2 A-C$ ), subiculum (Fig. 2D$F$ ), cerebral cortex (Fig. $2 G-I$ ), cerebellar cortex (Fig. $2 J-L$ ), and motor neurons in the facial nucleus (Fig. 2M-O). While expression levels of A-type FHFs were fairly uniform among motor neurons and pyramidal neurons in the hippocampus and subiculum, the levels of expression among cerebral and cerebellar cortical neurons were found to be highly variable (Fig. $2 G-L$ ).

Based upon the above expression pattern, potential modulation of excitability by A-type FHFs was studied in juvenile mouse hippocampal CA1 pyramidal neurons, as all of these neurons express A-type FHFs on their axon initial segments (Fig. 2A-C) and consistently exhibit classical spike accommodation (Thompson et al., 1985; Moyer et al., 1992; Chevaleyre and Siegelbaum,
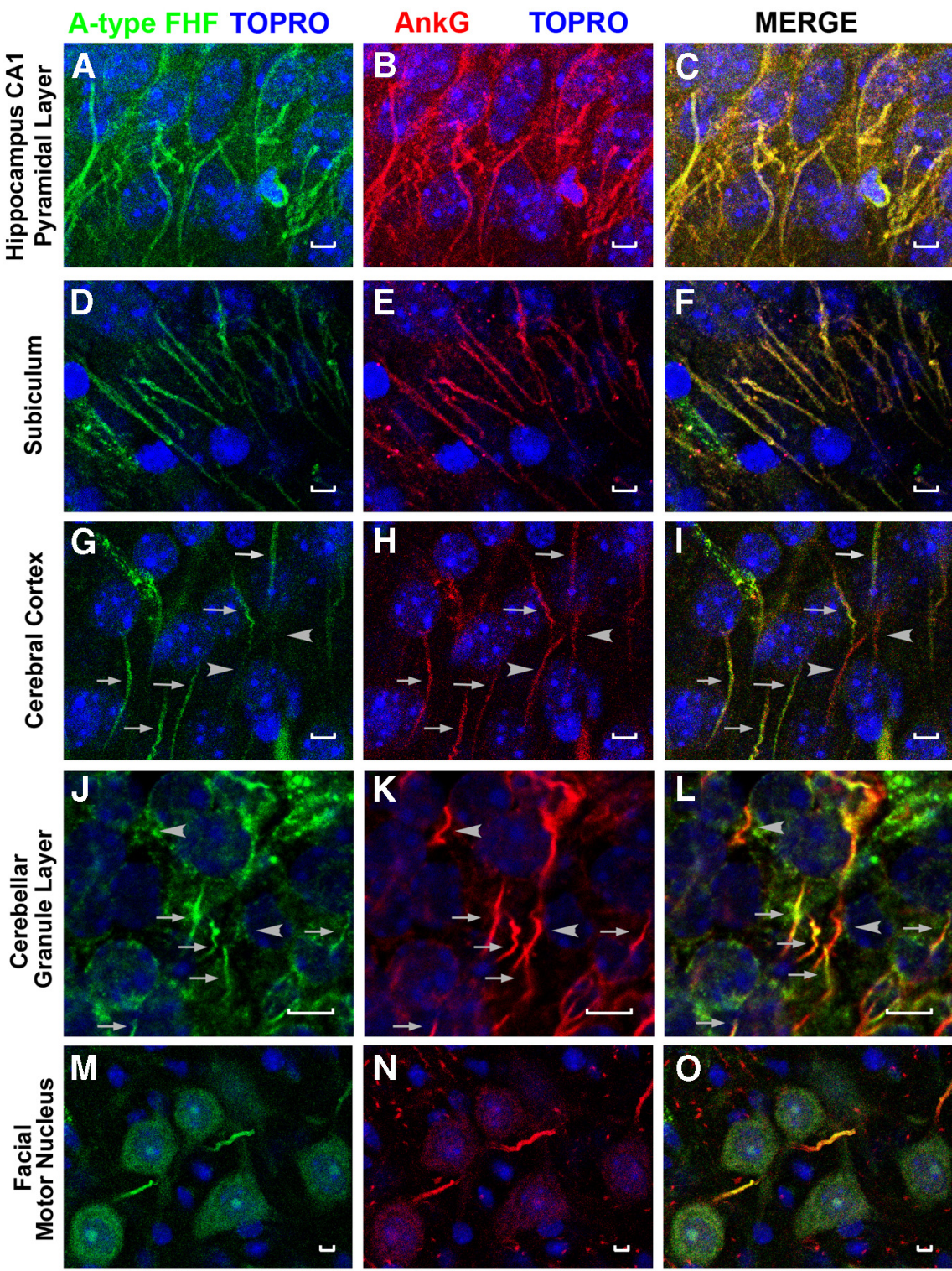

Figure 2. A-type FHF expression in juvenile mouse brain. Expression of A-type FHFs was probed in mouse hippocampus CA1 pyramidal region $(\boldsymbol{A}-\boldsymbol{C})$, subiculum $(\boldsymbol{D}-\boldsymbol{F})$, cerebral cortex $(\boldsymbol{G}-\boldsymbol{I})$, cerebellar cortical granule layer $(\boldsymbol{J}-\boldsymbol{L})$, and facial motor nucleus $(\boldsymbol{M}-\mathbf{0})$ by immunofluorescence detection with $\mathrm{N} 235 / 22$ monoclonal anti-A-type FHF plus Alexa 488 secondary antibody $(\boldsymbol{A}, \boldsymbol{D}, \mathbf{G}$ prominently colocalize with ankyrin $G$ on axon initial segments in all detected $C A 1$ and subicular pyramidal neurons $(\boldsymbol{A}-\boldsymbol{F})$ and motor neurons $(\boldsymbol{M}-\mathbf{0})$, and on some (arrows) but not other (arrowheads) cerebral cortical neurons and cerebellar granule layer neurons $(\mathbf{G}-\boldsymbol{L}$ ). Nuclei were visualized with TOPRO iodide (blue pseudocolor). Scale bar, $5 \mu \mathrm{m}$.

2010; S. Chen et al., 2014). An example of spike accommodation in a CA1 neuron in response to an $800 \mathrm{~ms}$ constant current injection is shown in Figure 3, $A$ and $B$. The firing pattern is stable over a 50 min recording period (Fig. $3 A, B$ ). In some neurons, firing initiated with a two- or three-spike burst followed by the accommodating train (Fig. $3 C, D$ ). When the same neurons were rerecorded 50 min after pipette break-in, the initial spike burst often dissipated (Fig. 3C, lower trace), but spike accommodation persisted (Fig. 3C,D). All nine neurons recorded in this manner retained spike accommodation over a $50 \mathrm{~min}$ recording period (Fig. 3I).

The stability of spike accommodation during extended recordings allowed for experiments with Mab N235/22 perfusion to test for accommodation's dependence upon A-type FHFs. To 
A

w/o $A b$
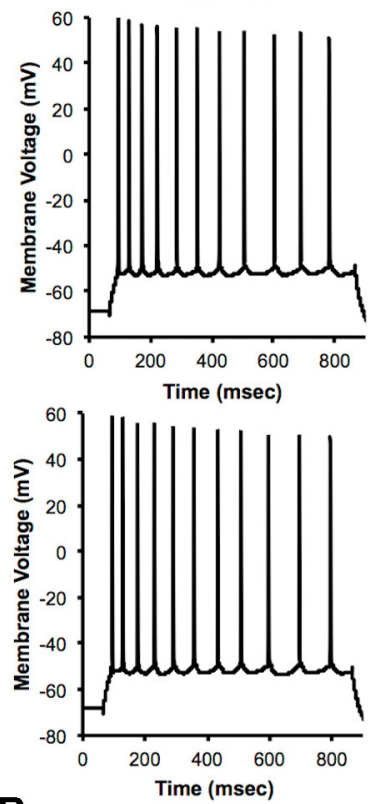

B

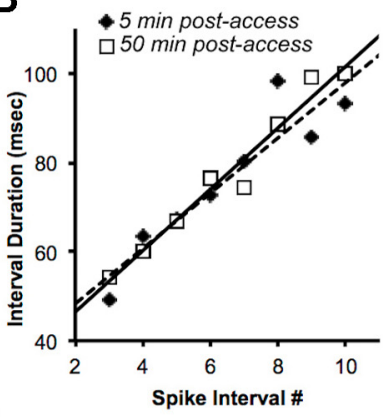

C
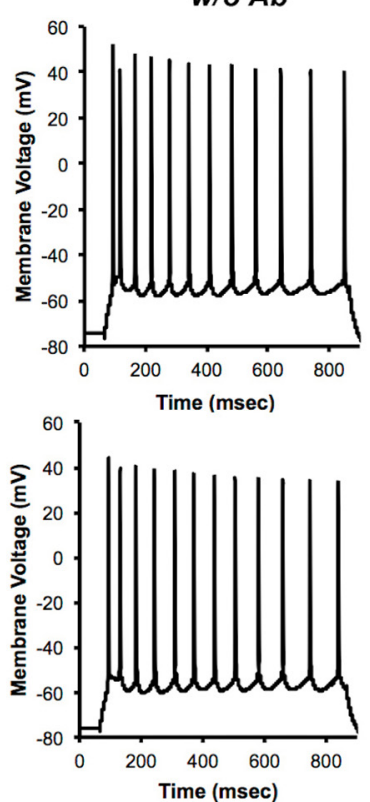

D

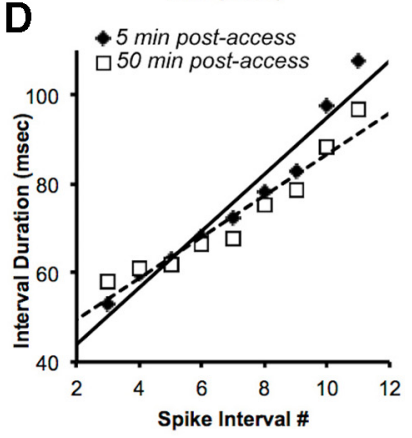

E
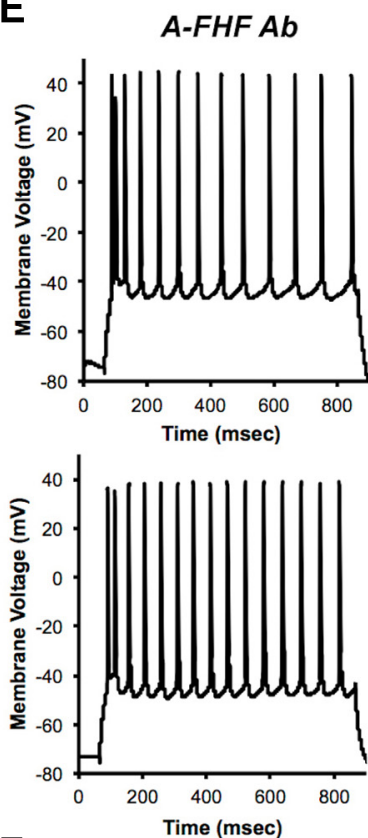

$\mathbf{F}$

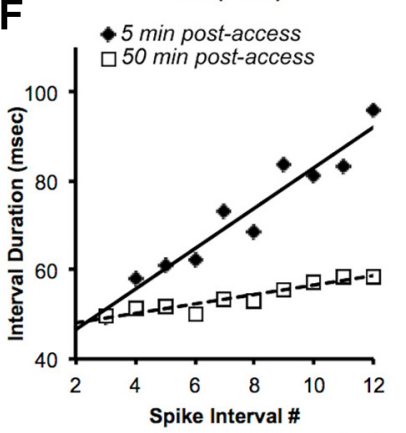

G
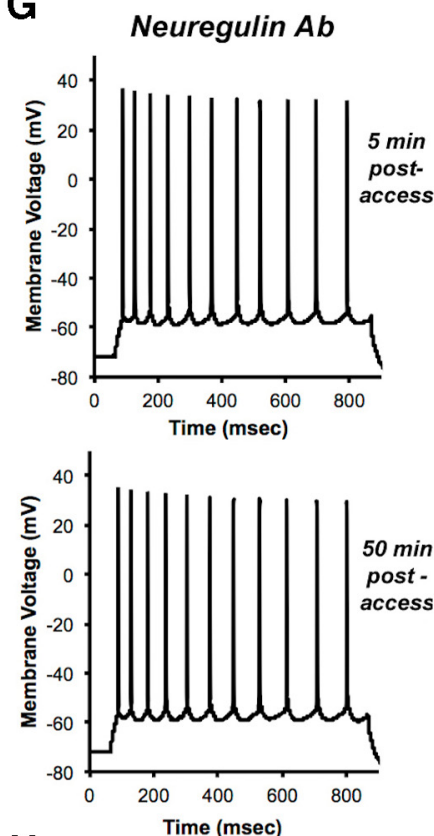

H

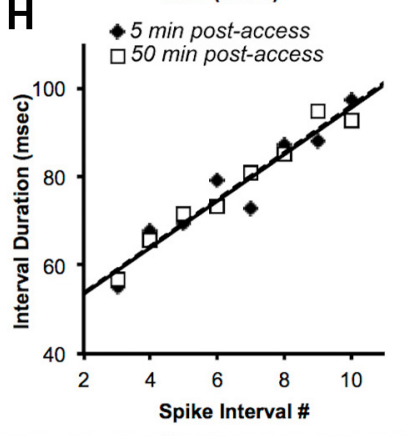

I
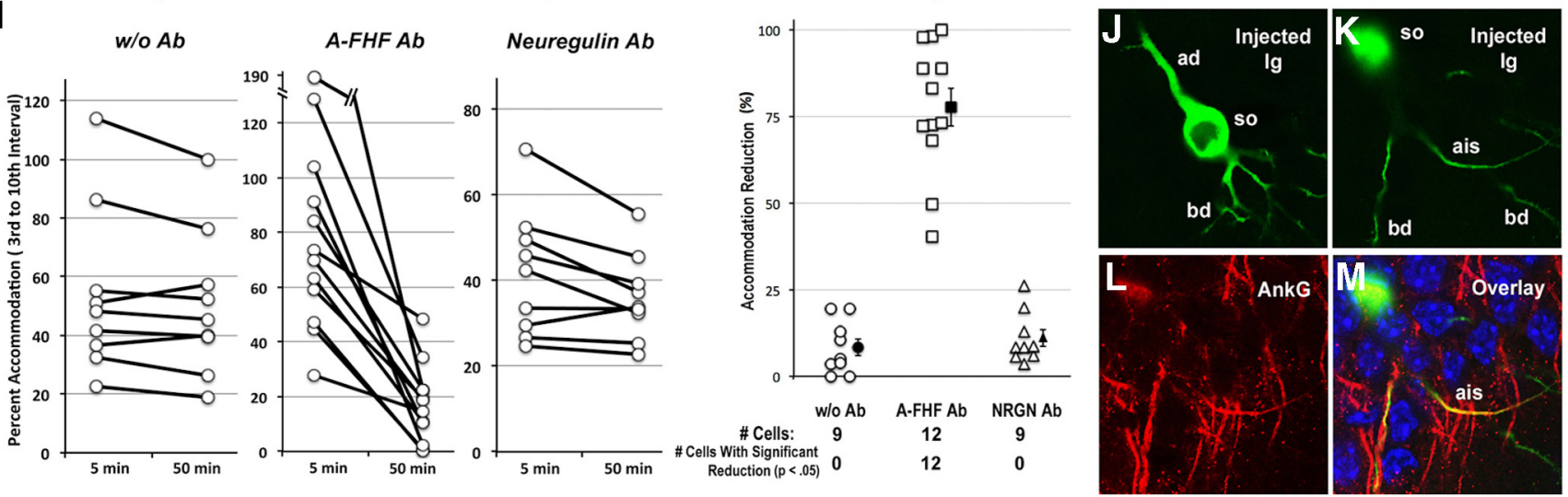

Figure 3. A-type FHF monoclonal antibody perfusion suppresses spike accommodation in hippocampal CA1 pyramidal neurons. Neurons were whole-cell patched with pipettes containing N235/22 A-type FHF Mab ( $\left(\mathrm{IG}_{2 b}\right)$, control Mab against neuregulin $\left(\mathrm{lgG}_{2 \mathrm{~b}}\right)$, or no antibody, and action potentials were recorded in response to constant current injection at 5 $\mathrm{min}$ and at $50 \mathrm{~min}$ post access. Spike trains are shown for current injections that gave a third spike-to-spike interval of $40-55 \mathrm{~ms}$. $A, B$, Cell patched without antibody showing accommodating spike train stable from 5 to $50 \mathrm{~min}$. Traces in $\boldsymbol{A}$, graph of spike intervals in $\boldsymbol{B}$ with least-squares linear fit. $\boldsymbol{C}, \boldsymbol{D}$, Another cell without antibody shows a two-spike burst followed by spike accommodation; the burst phenomenon dissipated, but accommodation was stable over 50 min recording. $E, F$, In cell patched with A-FHF Mab, at 5 min post access, the cell shows a two-spike burst followed by accommodating train, and accommodation was largely repressed following 50 min of perfusion. $\boldsymbol{G}, \boldsymbol{H}$, Cell patched with neuregulin Mab shows accommodation that is stable over 50 min of perfusion. $I$, For each recorded neuron, spike accommodation at 5 min and again at 50 min post access was quantitated and plotted as the percentage increase in the tenth interspike interval compared with the third interval. To the right is a scatter plot of accommodation reduction in all recorded cells, with each cell marked by open symbols and mean reduction and SE indicated as closed symbols. The significance of accommodation reduction for each cell was assessed by ANCOVA and indicated below the plot. $J-M$, Ig perfusion of a CA1 pyramidal neuron. CA1 neuron within a hippocampal slice was patched with pipette containing OregonGreen 488-conjugated nonspecific Ig, and the slice was fixed following $30 \mathrm{~min}$ perfusion and processed for confocal fluorescence. Perfused lg was detected in two optical planes of the cell $(\boldsymbol{J}, \boldsymbol{K})$ including all proximal processes. $\boldsymbol{L}$, Same optical field as $\boldsymbol{K}$ shows ankyrin $\boldsymbol{G}$ immunofluorescence, and overlay $(\boldsymbol{M})$ includes TOPRO nuclear fluorescence. So, soma; ad, apical dendrite; bd, basal dendrite; ais, initial segment. 
first ascertain whether antibody can passively perfuse from pipette into neuronal processes, a CA1 neuron was patched with a pipette filled with fluorescently tagged nonspecific Ig and fixed after $30 \mathrm{~min}$ of perfusion. As shown in Figure 3, $J-M$, fluorescent Ig readily perfused into the neuron's apical dendrites and basal processes, including the proximal axon, thereby demonstrating the technical efficacy of passive antibody perfusion. Figure 3, E and $F$, shows an example of recording from a Mab N235/22-perfused neuron. While spike accommodation was evident within $5 \mathrm{~min}$ of pipette break-in, it was virtually eliminated 50 min later. MAb $\mathrm{N} 235 / 22$ induced $77.4 \pm 5.7 \%$ inhibition of accommodation, with significant inhibition ( $p<0.005$ by ANCOVA) observed in all 12 tested neurons (Fig. 3I). Inhibition of spike accommodation was specific to A-type FHF antibody, as perfusion with an off-target monoclonal antibody (antineuregulin) of the same Ig isotype failed to induce significant block of spike accommodation in any of nine tested cells (Fig. 3G-I).

Classical accommodation in these CA1 neurons was accompanied by a gradual spike-to-spike rise in the voltage spike threshold (Fig. 4A,B). Following $50 \mathrm{~min}$ of MAb N235/22 perfusion, the threshold for successive spikes showed far less rise (Fig. 4C-E). Among all 11 neurons perfused with A-type FHF Mab, the rise in spike threshold between the 4th and 12th spike was highly significant at 5 min post access $\left({ }^{* *} p<0.001\right)$, but the rise was greatly reduced after 50 min of antibody perfusion and suppression of accommodation (Fig. 4F). These findings suggested that progressive loss of sodium channel availability due to A-type FHF-mediated channel long-term inactivation could be the underlying basis for spike accommodation (Miles et al., 2005; Platkiewicz and Brette, 2011).

A-type FHFs mediate long-term sodium channel inactivation in soma and proximal processes of hippocampal CA1 neurons

Since classical spike accommodation in hippocampal neurons was found to be A-type FHF dependent, we tested whether A-type FHFs mediate long-term inactivation of sodium channels residing in CA1 neurons. When a whole-cell patched neuron was subjected to eight $40 \mathrm{~ms}$ depolarizations to $0 \mathrm{mV}$ spaced by $40 \mathrm{~ms}$ recovery intervals at $-90 \mathrm{mV}$, channels associated with approximately one-quarter of the recorded sodium current accumulated into a long-term inactivated state (Fig. 5A). The long-term inactivated channels recovered at $-90 \mathrm{mV}$ with a time constant of $444 \pm 22 \mathrm{~ms}(n=8$, example; Fig. $5 D)$. These dynamics of wholecell recorded sodium channels in hippocampal neurons closely resemble the behavior of $\mathrm{Na}_{\mathrm{v}} 1.6$ channels in the presence of
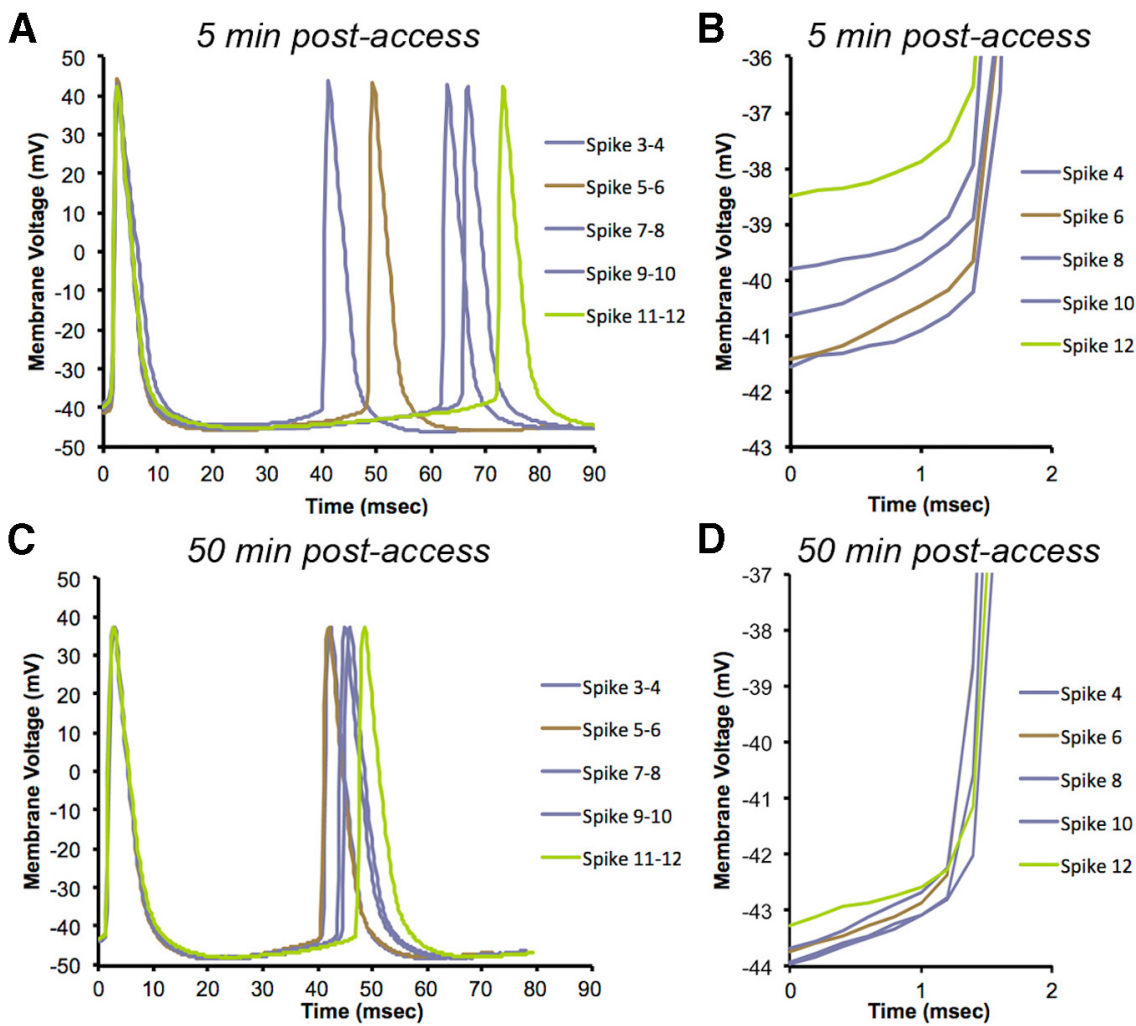

D 50 min post-access

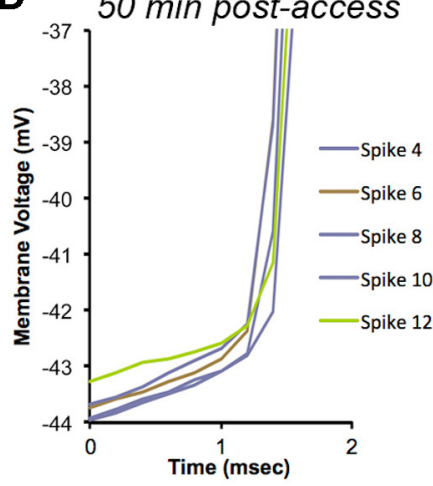

F

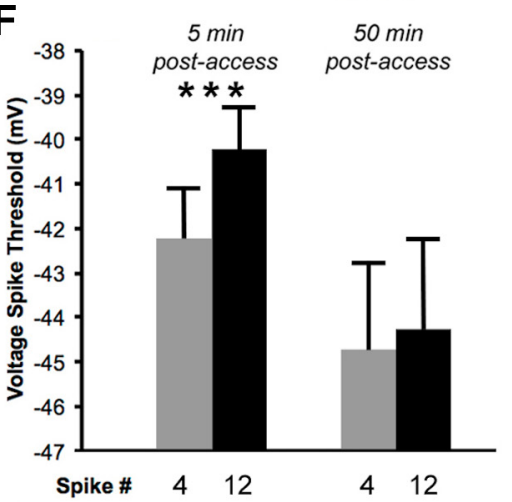

Figure 4. Voltage spike thresholds rise during spike accommodation. $A$, Spike pairs from an accommodating spike train are shown in overlapping traces with the first spike in each pair aligned. $\boldsymbol{B}$, Increasing spike-to-spike intervals are accompanied by progressively elevated spike thresholds, as shown in this enlargement of aligned superimposed spikes. When this same cell was perfused for 50 min with A-type FHF Mab N235/22, spike intervals showed greatly reduced accommodation $(\boldsymbol{C})$ and spike thresholds were nearly identical throughout spike train $(\boldsymbol{D}, \boldsymbol{E})$. Spike threshold rises approximately linearly during accommodation, with the 4th and 12 th spike is highly significant at 5 min post access $\left({ }^{* * *} p<0.001\right.$ by paired $t$ test), but the rise is greatly reduced after 50 min of antibody perfusion as accommodation is suppressed.

A-type FHFs (Fig. 1), although the data suggest that only a subset of neuronal channels is susceptible to long-term inactivation. Twenty-two cells were then patched using pipettes with or without MAb N235/22 and recordings were made at 5 and 20 min after pipette break-in (longer incubation with cesium-based pipette solution led to erosion of seal). In the absence of the A-type FHF antibody, channels associated with $24.8 \pm 0.7 \%$ of the sodium current underwent accumulating long-term inactivation that was still detectable when recording at 20 min post access (Fig. $5 A, C)$. In the presence of Mab N235/22, long-term inactivation was reduced to $9.4 \pm 1.5 \%$ of recorded sodium current after 20 min of perfusion (Fig. $5 B, C$ ), which represented a highly significant inhibition of inactivation $(p<0.0001$ by $t$ test). Hence, 
A

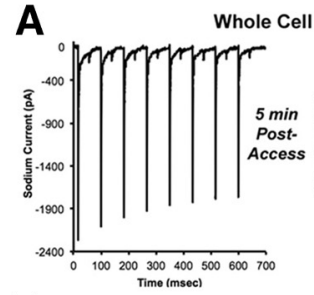

D

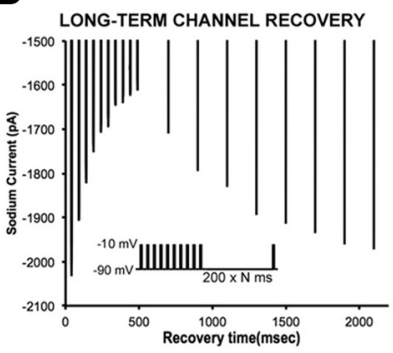

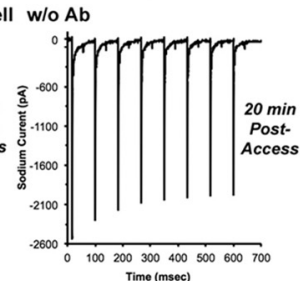

E

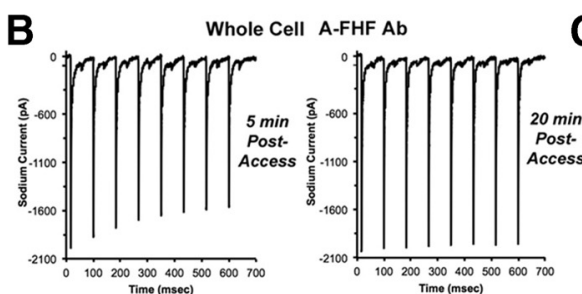

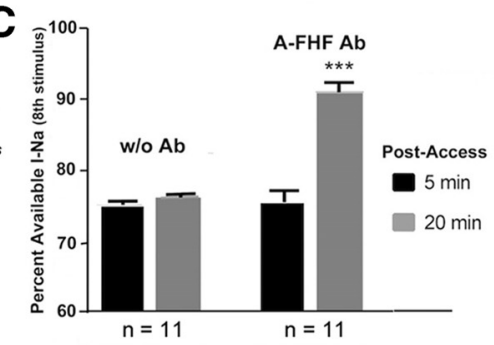
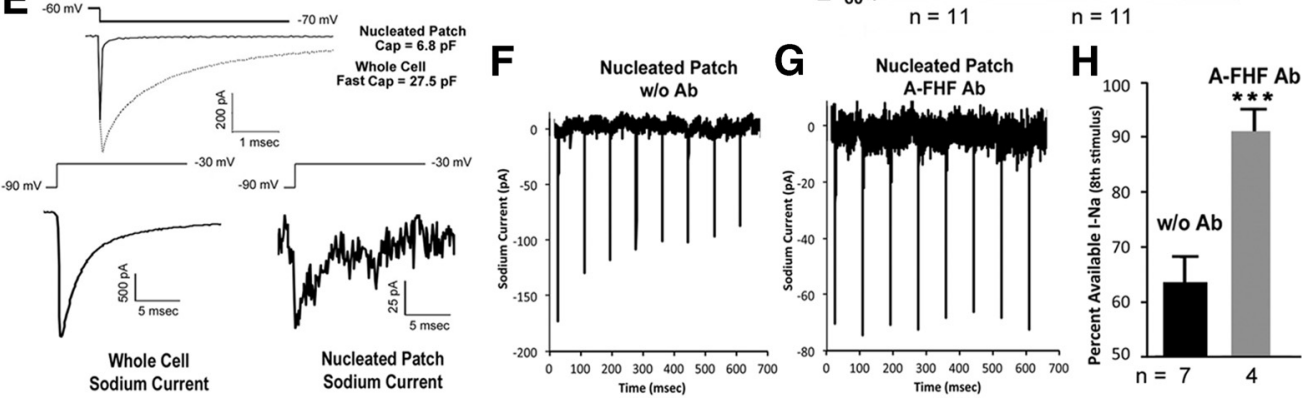

Figure 5. A-type FHF monoclonal antibody perfusion suppresses whole-cell and somatic sodium channel long-term inactivation in CA1 pyramidal neurons. $\boldsymbol{A}$, Sodium channel long-term inactivation in a CA1 neuron. Example of whole-cell recording from a neuron held at $-90 \mathrm{mV}$ and subjected to eight $40 \mathrm{~ms}$ depolarizations to $0 \mathrm{mV}$ spaced by $40 \mathrm{~ms}$, $-90 \mathrm{mV}$ recovery periods. Channels associated with approximately $20 \%$ of the sodium current accumulate into long-term inactivation when recorded 5 min post access (left), and the channel dynamics are reproduced when rerecorded at 20 min post access (right). $\boldsymbol{B}$, A-type FHF dependence of channel long-term inactivation. Another neuron recorded as in $\boldsymbol{A}$, except with N235/22 A-FHF Mab in patch pipette, and showing reduction in channel long-term inactivation after 20 min perfusion. $C$, Graphical display of long-term inactivation data recorded from all cells with A-FHF antibody $(n=11)$ and without antibody $(n=11)$. Antibody inhibits channel long-term inactivation after 20 min perfusion ( $\left.{ }^{* * *} p<0.0001\right)$. D, Recovery from long-term inactivation. Superimposed sodium current recordings of a neuron subjected to 10 brief depolarizations at $20 \mathrm{~Hz}$ and a subsequent test depolarization after recovery periods of $200-1600 \mathrm{~ms}$ (inset). The depolarization train drives $\sim 25 \%$ sodium channels into long-term inactivation that recover at $-90 \mathrm{mV}$ with Tau $=444 \pm 22 \mathrm{~ms}$ ( $n=8$ cells). $\boldsymbol{E}$, Sodium and capacitive currents in nucleated patch. A CA1 neuron in whole-cell configuration was hyperpolarized in voltage-clamp to quantify capacitive current (above) and depolarized to detect sodium current (below). A nucleated patch was then harvested from this cell, and both capacitive and sodium currents were recorded again. The nucleated patch capacitance represented $\sim 25 \%$ of the whole soma capacitance estimated from the fast decaying phase of the whole-cell capacitive current, but the nucleated patch sodium current was only $\sim 2.5 \%$ of the whole-cell sodium current, demonstrating that only $10 \%$ of the whole-cell sodium current was somatic in origin. $\boldsymbol{F}$, Long-term sodium channel inactivation in nucleated patch. A nucleated patch was extracted 20 min after accessing a CA1 neuron. Sodium currents were induced from the somatic membrane by eight depolarization cycles (as in $\boldsymbol{A}$ ) and showed accumulating current loss. G, A-type FHF dependence of somatic sodium channel long-term inactivation. Example of nucleated patch recording from a neuron perfused with A-type FHF antibody for $20 \mathrm{~min}$. There is no significant loss of sodium currents over eight depolarization cycles. $\boldsymbol{H}$, Graphical display of long-term inactivation data recorded from all nucleated patches with A-FHF antibody $(n=4)$ and without antibody $(n=7)$. Antibody inhibition of long-term inactivation is highly significant ( $\left.{ }^{* * *} p<0.0005\right)$.

A-type FHF blockade inhibits long-term inactivation of sodium channels recorded in the whole-cell configuration.

The whole-cell recorded sodium current reflects the combination of currents emanating from the soma and proximal processes. To assess the somatic contribution to the total sodium current and long-term sodium channel inactivation, nucleated patches were excised from whole-cell patched cells following a period of pipette perfusion with or without monoclonal antibody. Nucleated patches contained $\sim 25 \%$ of the somatic membrane, as judged by comparison of fast capacitive current transients elicited from whole-cell and nucleated patch configurations (Fig. 5E). Sodium current transients recorded from nucleated patches ranged from 60 to 150 pA (2-5\% of whole-cell sodium current; Fig. $5 F$ ), demonstrating that only $10-20 \%$ of sodium current from whole-cell recordings derives from channels residing in somatic membrane. Sodium channels associated with $35.7 \pm 3.8 \%$ of somatic sodium currents experienced accumulating long-term inactivation upon repetitive depolarizations (Fig. $5 F, H$ ), consistent with previous observation (Jung et al., 1997). However, when neurons were perfused with A-type FHF monoclonal antibody, channel long-term inactivation was significantly reduced to only $7.3 \pm 1.9 \%$ of the sodium conductance (Fig. $5 G, H ; p<0.0005$ by $t$ test). These results demonstrate that sodium channels in both the soma and in proximal processes are subject to A-type FHF-mediated long-term inactivation, and suggest that the somatic channels exhibit somewhat greater occupancy or sensitivity to A-type FHFs. We assume that the source of long-term inactivating extrasomatic sodium current is largely from the axon initial segment, as both sodium channels and A-type FHFs are clustered in this region of CA1 neurons (Fig. $2 A-C)$. However, long-term inactivation of sodium channels recorded from whole cells may also include a lesser contribution from proximal dendrites (Colbert et al., 1997; Jung et al., 1997).

In light of a recent report that some FHFs can influence voltage-gated calcium current density (Yan et al., 2013), we further surveyed voltage-gated calcium and potassium conductances for potential A-type FHF dependence in CA1 neurons. Calcium currents were recorded from voltage-clamped neurons in the presence of extracellular TTX, TEA, 4-AP, and cesiumbased pipette solution. Depolarization to $0 \mathrm{mV}$ from a $-90 \mathrm{mV}$ holding potential induced inward calcium current with slow time to peak and partial inactivation over a $200 \mathrm{~ms}$ time window (Fig. $6 A$ ), similar to prior observations (Brown and Griffith, 1983). The inactivated calcium conductance was very slow to recover, such that less calcium current was induced by a second depolarization following a $40 \mathrm{~ms},-90 \mathrm{mV}$ interval (Fig. 6A). Similar calcium currents were obtained following $30 \mathrm{~min}$ perfusion with A-type FHF antibody (Fig. 6B). The transient calcium current amplitude and its time-to-peak and decay rate, along with the amplitude of persistent calcium current, were not significantly affected by perfusion with monoclonal antibody (Fig. 6C-F). Potassium currents were recorded by applying voltage steps to neurons in the presence of extracellular TTX, $\mathrm{Cd}^{+2}$, and potassium-based pipette solution. In most neurons, depolarization induced a predominantly noninactivating outward current that was reproduced upon a second depolarization following a 40 

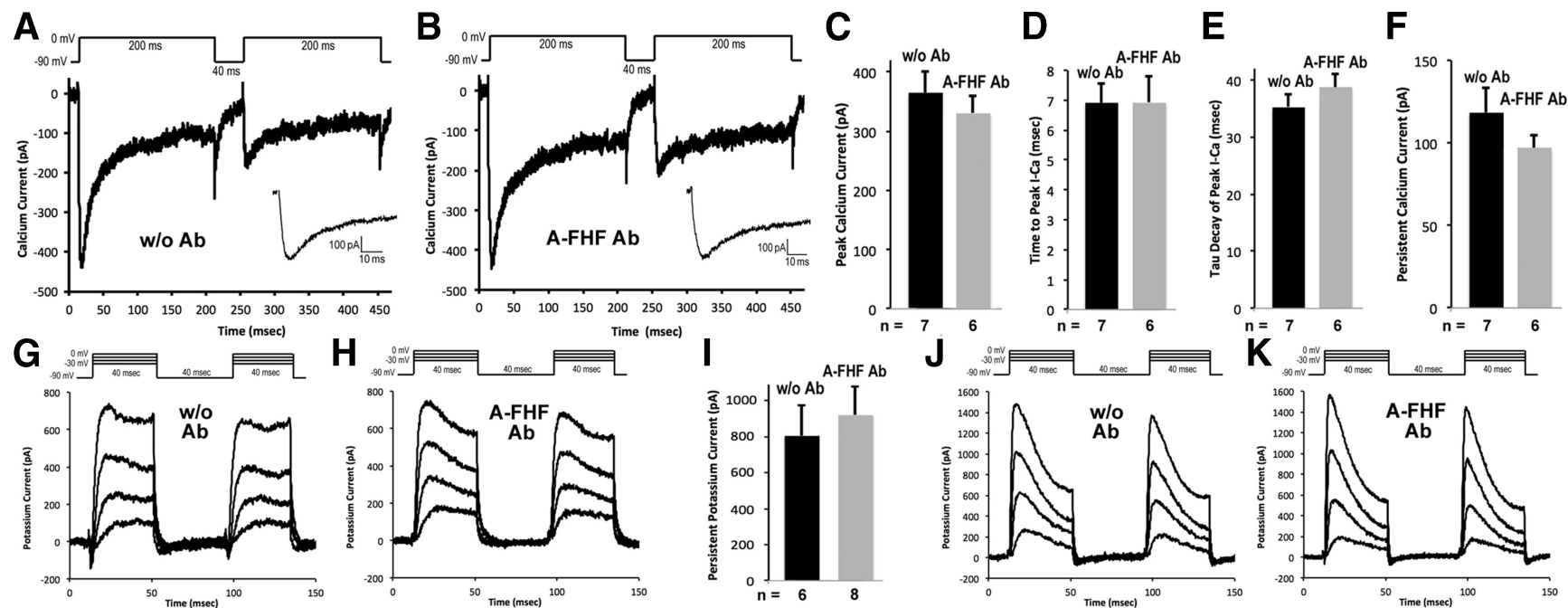

Figure 6. Voltage-gated calcium and potassium currents are not dependent upon A-type FHFs. $A$, Calcium currents in hippocampal CA1 neuron. A whole-cell patched neuron was subjected to two $200 \mathrm{~ms}$ depolarizations to $0 \mathrm{mV}$ with a $40 \mathrm{~ms}$ recovery interval (top) in extracellular and pipette solutions that isolate calcium current. Calcium current has transient and persistent components, and the transient component is largely unavailable following the $40 \mathrm{~ms}$ recovery phase. Inset shows timescale enlargement of the first transient current. $\boldsymbol{B}$, Calcium currents in neuron perfused with A-FHF antibody. Recording from a neuron perfused with A-type FHF monoclonal antibody for 20 min shows calcium currents qualitatively similar to $\boldsymbol{A}$. $\boldsymbol{C}-\boldsymbol{F}$, Quantification of calcium currents. Histogram charts summarize peak transient current $(\boldsymbol{C})$, time to peak $(\boldsymbol{D})$, transient current decay $(\boldsymbol{E})$, and persistent current $(\boldsymbol{F})$ for all cells $(n)$ recorded 20 min post access using pipettes with or without monoclonal antibody. No calcium current parameters are significantly affected by A-type FHF antibody perfusion. G, Potassium currents in hippocampal CA1 neuron. A whole-cell patched neuron was subjected to $40 \mathrm{~ms}$ depolarizations to between $-30 \mathrm{and} 0 \mathrm{mV}$ (top) in extracellular and pipette solutions that isolate potassium current. All current traces are superimposed. Most of the voltage-gated potassium current is noninactivating. $\boldsymbol{H}$, Potassium currents in neuron perfused with A-FHF antibody. Recording from a neuron perfused with A-type FHF monoclonal antibody for 20 min shows potassium currents qualitatively similar to $\mathbf{G}$. I, Histogram chart summarizing persistent current for all cells recorded 20 min post access using pipettes with or without monoclonal antibody. Potassium current amplitude is not significantly affected by A-type FHF antibody perfusion. $\boldsymbol{J}$, One of six recorded neurons showed large transient potassium current. $\boldsymbol{K}$, 0 ne of eight recorded neurons perfused with A-type FHF antibody also contained large transient potassium current.

ms recovery (Fig. 6G). The amplitude of the noninactivating potassium current was indistinguishable among neurons perfused in the presence of A-type FHF monoclonal antibody (Fig. $6 \mathrm{H}, \mathrm{I}$ ). Less frequently, neurons displayed substantial inactivating potassium current in either the absence (Fig. $6 J$ ) or presence (Fig. $6 \mathrm{~K}$ ) of monoclonal antibody.

From these current analyses, we can conclude that A-type FHFs mediate spike accommodation solely through their induction of accumulating long-term inactivation of sodium channels.

\section{An N-terminal open-channel blocking particle on A-type FHFs induces long-term inactivation of sodium channels} Having established the mechanism of classical accommodation and the first biological function of A-type FHFs, we conducted further experiments to clarify the mechanism of sodium channel modulation by A-type FHFs. A-type FHF-induced $\mathrm{Na}_{\mathrm{v}} 1.6$ longterm inactivation requires greater membrane depolarization than that required for channel fast inactivation (Dover et al., $2010)$. Although the half-maximal membrane voltage $\left(V_{1 / 2}\right)$ for $\mathrm{Na}_{\mathrm{v}} 1.6$ long-term inactivation in the presence of A-type FHFs was reported to be $\sim 7 \mathrm{mV}$ negative to $\mathrm{V}_{1 / 2}$ for channel activation (Dover et al., 2010), we have revisited whether long-term inactivation occurs only to channels reaching the open state. To more accurately compare the voltage dependence of channel transition into activated and long-term inactivated states, two important modifications were made to our prior recording protocols (see Material and Methods for rationale behind these changes). First, voltage commands and current recordings were now performed on Neuro2A cells expressing FHF2A and the fast inactivationdeficient mutant sodium channel $\mathrm{Na}_{\mathrm{v}} 1.6_{\mathrm{F} 1478 \mathrm{Q}}^{\mathrm{TTXr}}$ (Dover et al., 2010). Second, channel activation and long-term inactivation were now tested in a revised three-step protocol consisting of a brief $5 \mathrm{~ms}$ variable-step depolarization, a $40 \mathrm{~ms},-90 \mathrm{mV}$ recov- ery phase, and a subsequent depolarization to $0 \mathrm{mV}$; channel activation is thereby reported by sodium current induced in the first depolarization, and the extent of long-term inactivation induced during the first depolarization is reported by the reduction of sodium current elicited by the second depolarization after the $40 \mathrm{~ms}$ recovery period. Figure $7 A$ shows sodium current traces obtained from one cell with the revised voltage-clamp protocol, and Figure $7 B$ contains the graphical analysis of voltage dependence of sodium channel activation and long-term inactivation for all recorded cells. The voltage dependence of channel activation $(-30.6 \pm 1.0 \mathrm{mV})$ and FHF-mediated long-term inactivation $(-30.3 \pm 1.6 \mathrm{mV})$ were indistinguishable in this assay.

The above finding demonstrated that very similar voltagedependent sodium channel transitions are needed to open the channel and to render it susceptible to FHF-mediated long-term inactivation, suggesting that A-type FHFs act as open-channel blockers. We investigated this possibility more directly by testing whether the A-type FHF inactivation particle and a known open channel-blocking particle associated with the accessory channel subunit $\mathrm{Na}_{\mathrm{v}} \beta 4$ mutually compete for binding to open sodium channels. A short peptide corresponding to an epitope in the cytoplasmic domain of $\mathrm{Na}_{\mathrm{v}} \beta 4\left(\beta 4_{154-167}\right)$ has been shown to block the open sodium channel conductance path at positive membrane potentials and to rapidly dissociate upon membrane repolarization, thereby generating resurgent sodium current before channel deactivation (Grieco et al., 2005; G.K. Wang et al., 2006; Bant and Raman, 2010; Theile et al., 2011), which is thought to underlie the ability of certain types of neurons to fire at very high frequencies (Raman and Bean, 1997; Khaliq et al., 2003; Castelli et al., 2007). Our experiment required use of a different sodium channel, as ectopically expressed $\mathrm{Na}_{\mathrm{v}} 1.6$ does not readily generate resurgent current in the presence of $\mathrm{Na}_{v} \beta 4$ protein (Y. Chen et al., 2008) or $\mathrm{Na}_{\mathrm{v}} \beta 4$-derived blocking peptide (data not shown). Therefore, we 
A

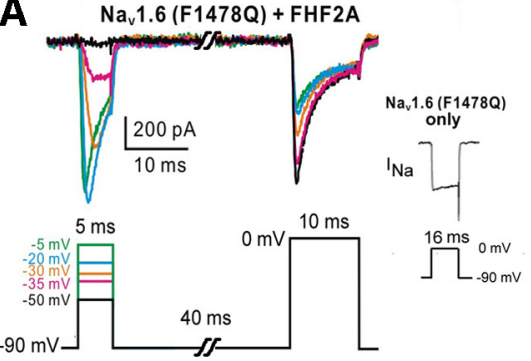

C

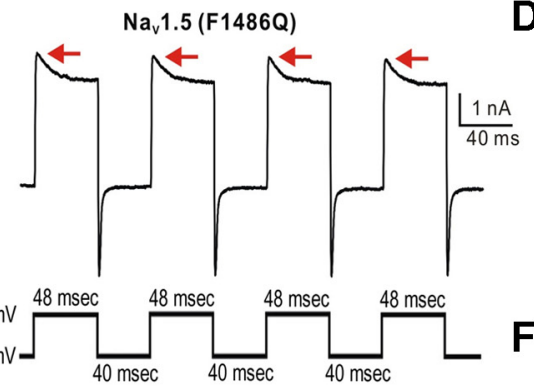

E

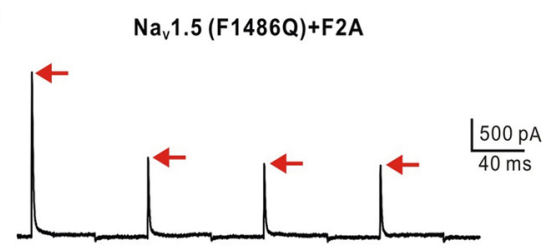

G

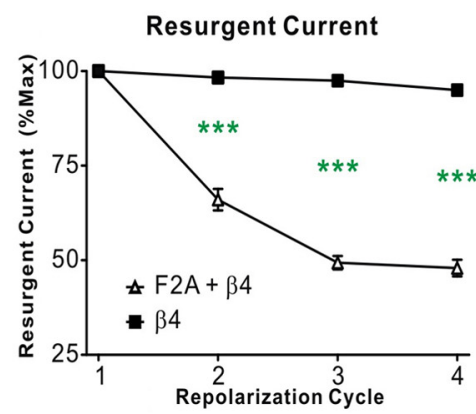

B

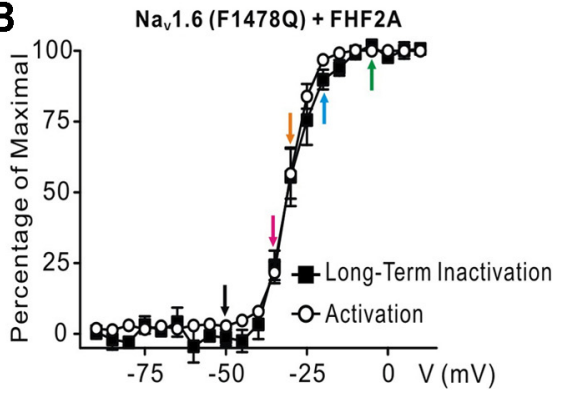

D

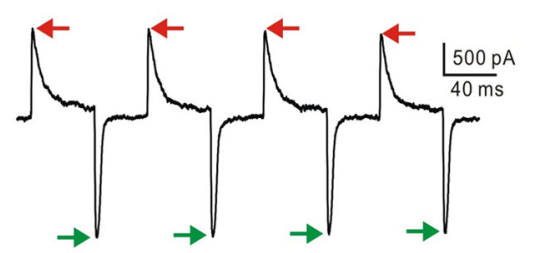

\section{$\leftarrow$}

$\mathrm{Na}_{v} 1.5(\mathrm{~F} 1486 \mathrm{Q})+\mathrm{F} 2 \mathrm{~A}+\beta 4$

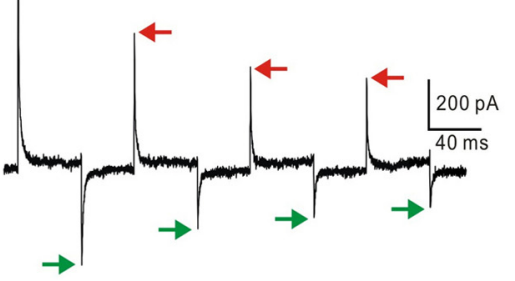

H

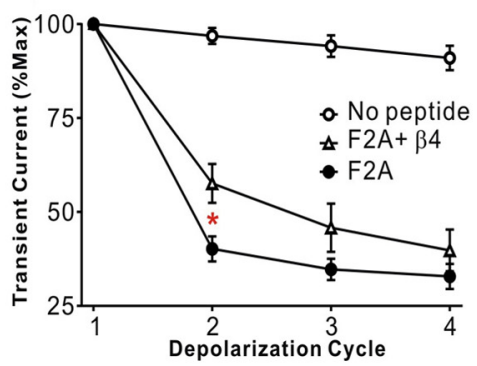

Figure 7. The N-terminal long-term inactivation particle of FHF2A induces open-channel block. $\boldsymbol{A}, \boldsymbol{B}$, Coincident voltage dependence for $\mathrm{Na}_{\mathrm{v}} 1.6_{\mathrm{F} 1478 \mathrm{Q}}$ activation and FHF2A-dependent long-term inactivation. Sodium currents in Neuro2A cells expressing fast inactivation-defective $\mathrm{Na}_{\mathrm{v}} 1.6_{\mathrm{F} 14780}$ and FHF2A were recorded during voltage sweeps consisting of a 5 ms variable-step depolarization, $40 \mathrm{~ms}$ recovery at $-90 \mathrm{mV}$, and second depolarization to $0 \mathrm{mV}$ ( $\boldsymbol{A}$, bottom). Currents from several sweeps are superimposed $(\boldsymbol{A})$, showing that voltages initially activating sodium channels trigger long-term inactivation. Inset trace is from a cell expressing $\mathrm{Na}_{\mathrm{v}} 1.6_{\mathrm{F} 14780}$ only and showing virtually no channel inactivation during a $16 \mathrm{~ms}$ depolarization to $0 \mathrm{mV}$. B, Superimposed plots of voltage dependence for channel activation and long-term inactivation in all cells $(n=6)$. Colored arrows highlight voltages displayed in $\boldsymbol{A}$. $\mathbf{C}-\boldsymbol{H}$, The $\mathrm{Na}_{\mathrm{v}} \beta 4$ blocking particle and FHF2A long-term inactivation particle compete for binding to $\mathrm{Na}_{\mathrm{v}} 1.5$ open channels. Sodium currents were recorded in Neur02A cells expressing fast inactivation-defective $\mathrm{Na}_{\mathrm{v}} 1.5_{\mathrm{F} 1486 \mathrm{Q}}$ with bath and pipette solutions shifting the sodium reversal potential to $-10 \mathrm{mV}$. Four depolarizations to $+70 \mathrm{mV}$ were spaced by 40 $\mathrm{ms},-100 \mathrm{mV}$ recovery periods (C, bottom). $\boldsymbol{C}$, No peptide in pipette: equivalent and largely noninactivating outward currents were generated at each depolarization (red arrows), with brief inward tail currents upon repolarizations. D, 1 mm $\beta 4_{154-167}$ peptide in pipette: equivalent outward currents (red arrows) were transient due to $\beta 4$ block, and each repolarization generated comparable inward resurgent current (green arrows). $\boldsymbol{E}$, One micrometer $\mathrm{F}_{2 \mathrm{~A}_{2-18}}$ peptide in pipette: all transient outward current upon depolarization was fully blocked by peptide and $\sim 35 \%$ of channels recovered after $40 \mathrm{~ms}$ at $-100 \mathrm{mV}$, resulting in smaller outward currents upon depolarizations 2, 3, and 4 (red arrows). Stable peptide binding precluded resurgent current upon -100 $\mathrm{mV}$ repolarizations. $\boldsymbol{F}, \beta 4_{154-167}$ and $\mathrm{F}_{2-18}$ peptides (1 mM each) in pipette: transient outward currents (red arrows) and resurgent inward currents (green arrows) both progressively decreased. All channels are blocked by either $\beta 4$ or F2A peptide in the first depolarization, with $\beta 4$ binding preventing maximal long-term inactivation by F2A (transient current $2>3>4$ ), and stable F2A binding progressively blocking $\beta 4$-mediated resurgent currents. G, Plot of resurgent currents from cells containing $\beta 4$ peptide $(n=5)$ or $\beta 4+$ F2A peptides $(n=6)$. Resurgent current is significantly decreased upon repolarizations 2,3 , and 4 $\left({ }^{* *} p<0.0001\right) . \boldsymbol{H}$, Plot of depolarization-induced transient currents from cells containing no peptide $(n=4), \mathrm{F} 2 \mathrm{~A}$ peptide $(n=6)$, or $\beta 4+$ F2A peptides $(n=6)$. The second-cycle transient current inhibition by F2A is significantly suppressed by $\beta 4$ peptide $\left({ }^{*} p<0.02\right)$. used a mutant fast inactivation-defective cardiac sodium channel $\mathrm{Na}_{\mathrm{v}} 1.5_{\mathrm{F} 1486 \mathrm{Q}}$. G.K. Wang et al. (2006) have shown that cells ectopically expressing this channel and patched with a pipette containing $\beta 4_{154-167}$ peptide under conditions that reduce the sodium reversal potential experience outward sodium current at strong positive membrane potential, which is quickly blocked by $\beta 4$ peptide and subsequent inward resurgent current upon membrane repolarization. Therefore, we assayed sodium currents in Neuro2A cells ectopically expressing $\mathrm{Na}_{\mathrm{v}} 1.5_{\mathrm{F} 1486 \mathrm{Q}}$ using pipettes containing $\beta 4_{154-167}$ peptide and/or an A-type FHF-derived peptide $\left(\mathrm{F}_{2} \mathrm{~A}_{2-18}\right)$, which is able to induce channel long-term inactivation (Dover et al., 2010).

In the absence of peptides, a series of depolarizations to $+70 \mathrm{mV}$ applied to $\mathrm{Na}_{\mathrm{v}} 1.5_{\mathrm{F} 1486 \mathrm{Q}}$-expressing cells generated weakly inactivating outward sodium currents (Fig. $7 C$, red arrows), each time followed by an instantaneous inward tail current preceding channel deactivation upon shift to $-100 \mathrm{mV}$ (Fig. 7C). In the presence of $\beta 4_{154-167}$, open channels underwent block at $+70 \mathrm{mV}$ terminating the outward current, and then briefly reopened upon shift to $-100 \mathrm{mV}$ generating a resurgent inward current (Fig. $7 D$, green arrows), recapitulating prior published studies (G.K. Wang et al., 2006). $\mathrm{F}^{2} \mathrm{~A}_{2-18}$ peptide, in contrast, terminated outward sodium current and drove the channels into a longer term inactivated state such that only some of the channels recovered within $40 \mathrm{~ms}$ at -100 $\mathrm{mV}$ (Fig. 7E, red arrows). $\mathrm{F}_{2} \mathrm{~A}_{2-18}$ peptide block did not allow for resurgent sodium current, as the peptide remained tightly bound to the channel after the shift from $+70 \mathrm{mV}$ to $-100 \mathrm{mV}$ (Fig. $7 E$ ). Mutual competition for channel binding was seen when both peptides were present. While some resurgent current was observed upon the first repolarization, reflecting the block of some channels by $\beta 4_{154-167}$ during the initial depolarization, resurgent current declined following subsequent repolarization cycles (Fig. $7 F, G$ ), demonstrating an accumulating inhibition of $\beta 4_{154-167}$ channel binding by $\mathrm{F}_{2} \mathrm{~A}_{2-18}$ peptide. Reciprocally, $\beta 4_{154-167}$ channel binding during the initial depolarization cycle modestly, but significantly, impaired F2 $\mathrm{A}_{2-18}$-mediated channel long-term inactivation, which was enhanced in subsequent depolarization cycles (Fig. 7F,H). The mutual competition for channel binding between A-type FHF- and $\mathrm{Na}_{\mathrm{v}} \beta 4$-derived peptides confirms that these proteins have overlapping binding sites within open sodium channels. 
A

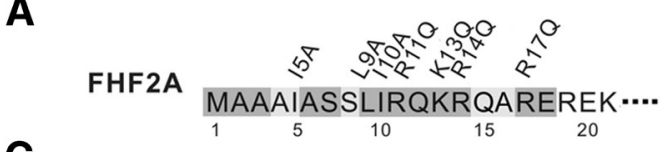

C

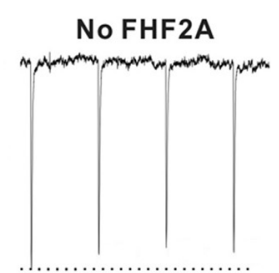

FHF2A R14Q

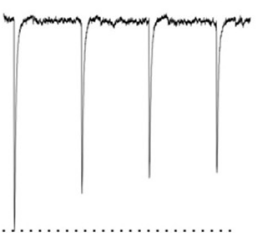

E
B LONG-TERM INACTIVATION ASSAY PROTOCOL

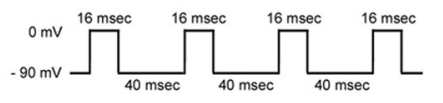

D
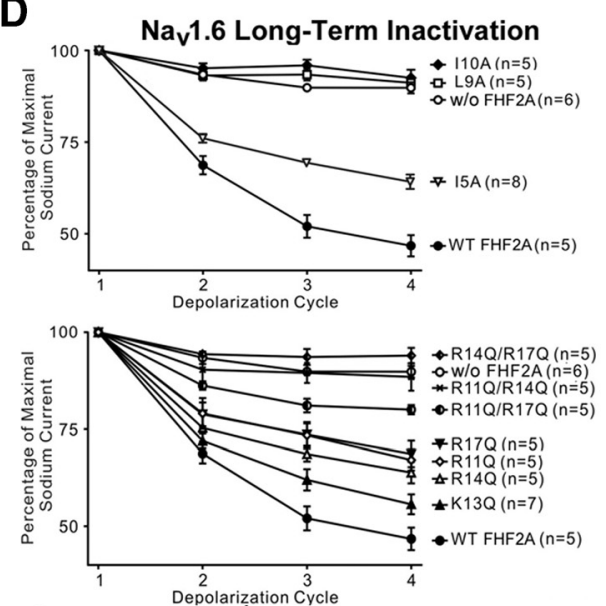
y

$\mathrm{Na}_{\mathrm{v}} 1.6$ Long-Term Inactivation Recovery FHF2A R11Q/R17Q
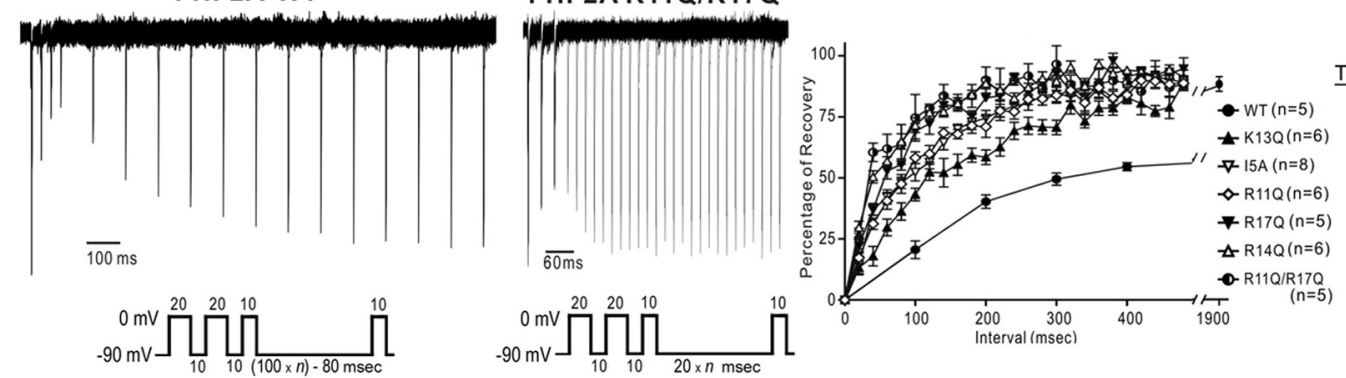

TAU (msec)

437

162

116

105

57

Figure 8. Essential aliphatic and cationic residues in the FHF2A long-term inactivation particle. $\boldsymbol{A}, \mathrm{N}$-terminal sequence of FHF2A. Residues identical in all four A-type FHFs are dark shaded, residues identical in three of the four A-type FHFs are light shaded, and engineered single-residue mutations are indicated. $\boldsymbol{B}$, Voltage-clamp protocol for sodium channel accumulating long-term inactivation. C, Representative $\mathrm{Na}_{v} 1.6$ current traces for Neuro2A cells expressing wild-type and mutant FHF2A proteins. Mutations reduce or eliminate channel long-term inactivation. All mutated FHF2A proteins $(\boldsymbol{A})$ retain ability to induce depolarizing shift in voltage dependence of fast inactivation (data not shown). $\boldsymbol{D}$, Accumulating long-term inactivation induced by all FHF2A proteins with aliphatic residue substitutions (upper graph) and cationic residue substitutions (lower graph). For each FHF, the number of cells tested is in parentheses. $\boldsymbol{E}$, FHF2A mutations accelerate recovery from long-term inactivation. Superimposed recording traces from voltage-clamp protocols (insets left and middle) consisting of three rapid depolarizations and a fourth test depolarization after a variable duration recovery period. Recovery from long-term inactivation is much faster in cells expressing FHF2A $A_{R 110 / R 170}$ (middle) compared with wild-type FHF2A (left). All FHF2A mutations impairing accumulation of $\mathrm{Na}_{\mathrm{v}} 1.6$ long-term inactivation (D) facilitate recovery from inactivation (right). Inset shows number of cells tested for each FHF ( $\boldsymbol{n}$ value) and time constant (Tau) for recovery at $-90 \mathrm{mV}$.

Multiple residues within A-type FHFs contribute to induction and maintenance of long-term inactivation

The individual residues near the $\mathrm{N}$ terminus of FHF2A required for induction of $\mathrm{Na}_{\mathrm{v}} 1.6$ long-term inactivation were determined by engineering substitutions at aliphatic and basic residues (Fig. $8 A$ ) and assaying transfected Neuro2A cells using the four-cycle depolarization protocol (Fig. $8 B$ ). Representative current traces are shown in Figure $8 C$, while long-term inactivation of all mutant FHFs are graphically represented (Fig. 8D). Alanine substitutions at either Leu-9 or Ile-10 completely suppressed channel long-term inactivation (Fig. $8 D$ ), while Ile-5 substitution caused mild impairment as manifested by less accumulation of channels into the long-term inactivated state (Fig. $8 D$ ) and faster recovery from long-term inactivation (Fig. $8 E$ ). The effect of mutagenesis on recovery rate argues that the FHF $\mathrm{N}$ terminus maintains the inactivation state and does not simply catalyze entry into this state. Additionally, glutamine substitutions at any one of the basic residues, Arg-11, Lys-13, Arg-14, or Arg-17, caused impairment of long-term inactivation accumulation and hastened recovery (Fig. 8D,E), while double substitutions at Arg-11/ Arg-14 or Arg-14/Arg-17 completely suppressed long-term inac- tivation (Fig. 8D). None of these substitutions significantly affected the ability of FHF2A to modulate steady-state fast inactivation (data not shown). Therefore, the $\mathrm{N}$ termini of A-type FHFs rely upon their extensive hydrophobic and cationic character for binding as open-channel blocking particles and maintaining the long-term inactivated state. The role of the FHF blocking particle in maintaining sodium channel long-term inactivation serves as further evidence that fast-onset long-term inactivation and slow inactivation are distinct channel states (see Discussion).

\section{Discussion}

FHFs modulate sodium channel gating and neuronal intrinsic excitability in complex ways. Proteins encoded by the genes Fhf4 and Fhf1 had been shown previously to promote excitability in cerebellar granule and Purkinje neurons by raising the voltage dependence of sodium channel fast inactivation or by enhancing sodium current density (Goldfarb et al., 2007; Shakkottai et al., 2009). While A-type FHFs also raise the voltage dependence of fast inactivation and are likely to initially facilitate action potential generation (Lou et al., 2005; Rush et al., 2006; Dover et al., 2010), we show here that A-type FHFs foster progressively re- 
duced firing (classical accommodation) in hippocampal neurons by promoting accumulating long-term sodium channel inactivation. Action potentials mediated by current injection cumulatively reduce channel availability, thereby delaying firing by raising voltage spike threshold. Thus, classical accommodation in these neurons is mediated by the combination of progressively declining available sodium conductance driven by FHFs and progressively increasing M-type potassium conductance carried by Kv7 channels during the spike train (Otto et al., 2006).

Only $\sim 25 \%$ of the sodium current in whole-cell recordings of CA1 neurons was susceptible to long-term inactivation, suggesting that A-type FHFs are associated with only a subset of channels in these cells due either to limited levels of FHF expression or to differential FHF affinity toward sodium channel isoforms. Different classes of neurons are likely to achieve distinct firing properties in part through expression of specific combinations of FHF isoforms (Goldfarb et al., 2007; Wozniak et al., 2007) together with potentially different distributions of FHFs within the axon initial segment (Xiao et al., 2013).

The broad expression of A-type FHFs on axon initial segments of neurons across the CNS suggests that these FHFs have widespread effects on neural excitability. As one intriguing example, spinal motor neurons exhibit classical accommodation that cannot be attributed to calcium-activated or M-type potassium currents (Miles et al., 2005). These neurons also exhibited fast-onset long-term sodium channel inactivation (Miles et al., 2005) and motor neurons also express A-type FHFs (Fig. 2M-O), suggesting a similar mechanism of accommodation to that described here for hippocampal neurons.

While spike accommodation was almost always observed in CA1 neurons, spike attenuation (defined as diminishing spiketo-spike amplitude) was highly variable and sometimes absent in our experiments (Fig. 3E), similar to results reported previously (Colbert et al., 1997). In one neuron, attenuation of $7 \mathrm{mV}$ was largely retained during monoclonal A-type FHF antibody perfusion even as spike accommodation was suppressed (data not shown), suggesting that A-type FHFs are not critical mediators of attenuation in this cell type. Hence, a partial loss in sodium channel availability during repetitive firing can substantially increase time-to-spike threshold with lesser effects on spike amplitude. We speculate that each action potential is triggered during a current injection-driven slow voltage ramp when a small sodium current onset drives the feedforward opening of all available sodium channels. As accumulating long-term inactivation reduces channel availability, the slow voltage ramp persists longer to a higher voltage threshold to allow for the same critical sodium current to be generated from fewer available channels.

Hippocampal CA1 neurons exhibit fast-onset long-term inactivation of sodium channels residing in the axon initial segment, the soma (Jung et al., 1997; Martina and Jonas, 1997; Fig. 5F), and on dendritic membranes (Colbert et al., 1997; Jung et al., 1997). It remains to be determined whether A-type FHFs are also responsible for dendritic channel long-term inactivation and attenuation of backpropagating sodium dendritic spikes characterized in these cells (Andreasen and Lambert, 1995; Callaway and Ross, 1995; Colbert et al., 1997; Jung et al., 1997).

Many features of FHF-mediated sodium channel long-term inactivation are comparable to the behavior of sodium channels in the giant axon of the worm Myxicola (Rudy, 1981), including millisecond-range onset, second-range recovery, cumulative entry, and accelerated recovery at hyperpolarized membrane potential. However, FHF genes are only found in vertebrates and their ancestral chordates (Popovici et al., 2005). Therefore, a second molecular mechanism must exist for fast-onset long-term inactivation exploited in Myxicola that results from an intrinsic sodium channel property or driven by an accessory molecule other than FHFs.

A-type FHFs bear an N-terminal particle that mediates openchannel block and long-term inactivation of voltage-gated sodium channels. The slow recovery of blocked channels likely reflects a large surface of interaction between the blocking particle and the channel pore, as seven highly conserved aliphatic and cationic amino acid residues on the 17-mer FHF2A particle contribute to long-term channel block (Fig. 8). Prior studies had suggested that the fast-onset long-term inactivation state in CA1 neurons and the slow inactivation state of sodium channels are mechanistically equivalent and arrived at through different transitions (Mickus et al., 1999). Since that time, several studies have referred to fast-onset accumulating long-term inactivation as slow inactivation (Miles et al., 2005; Aman and Raman, 2007; Milescu et al., 2010). However, our finding that A-type FHF $\mathrm{N}$-terminal residues are needed for maintenance of long-term inactivation at strong negative membrane potential (Fig. $8 E$ ) argues that this state is structurally distinct from the slow inactivation state.

The blocking particle of another sodium channel binding protein, $\mathrm{Na}_{\mathrm{v}} \beta 4$, appears to have a similar physical mechanism for inducing channel block, as both A-type FHF and $\mathrm{Na}_{\mathrm{v}} \beta 4$ particles compete for binding to open channels, and both particles rely upon hydrophobic and cationic residues. However, the different physiological consequence of $\mathrm{Na}_{\mathrm{v}} \beta 4$ channel block is the result of rapid $\beta 4$ particle dissociation upon repolarization, which produces pro-excitatory resurgent sodium current before channel deactivation or inactivation (Grieco et al., 2005; Aman and Raman, 2010; Theile et al., 2011). Although A-type FHF and $\mathrm{Na}_{\mathrm{v}} \beta 4$ particles can compete to some extent for binding to sodium channels in the ectopic Neuro2A cell system described here, it remains to be determined whether these channel modifiers interplay in vivo. Accommodating hippocampal pyramidal neurons expressing A-type FHFs do not generate resurgent current (Raman and Bean, 1997; Cannon and Bean, 2010) nor express $\mathrm{Na}_{\mathrm{v}} \beta 4$ (Grieco et al., 2005). However, cerebellar granule neurons express $\mathrm{Na}_{\mathrm{v}} \beta 4$ and generate resurgent current (Bant and Raman, 2010) while also expressing A-type FHFs (Fig. $2 J-L$ ), suggesting possible interplay between these two open-channel blockers in some neural cell types.

These functional experiments were made possible by the availability of highly potent pan-A-type FHF monoclonal antibody (N235/22) that specifically neutralizes the long-term inactivation particle of several A-type FHFs without affecting either A-type FHF-mediated modulation of steady-state fast inactivation of sodium channels or the activity of other protein isoforms encoded by FHF genes. The achievement of similar breadth and specificity of long-term inactivation suppression by genetic engineering may require generating exon $1 \mathrm{~A}$ missense mutations in each of the four FHF genes. While such mutant animals are currently unavailable, the advent of new high-efficiency gene-editing technology (Ran et al., 2013; H. Wang et al., 2013) may allow for future generation of mutant mice to assess the neurophysiological and behavioral consequences of A-type FHF-dependent classical accommodation.

\section{References}

Aman TK, Raman IM (2007) Subunit dependence of Na channel slow inactivation and open channel block in cerebellar neurons. Biophys J 92: 1938-1951. CrossRef Medline 
Aman TK, Raman IM (2010) Inwardly permeating Na ions generate the voltage dependence of resurgent $\mathrm{Na}$ current in cerebellar Purkinje neurons. J Neurosci 30:5629-5634. CrossRef Medline

Andreasen M, Lambert JD (1995) Regenerative properties of pyramidal cell dendrites in area CA1 of rat hippocampus. J Physiol 483:421-441. Medline

Aracri P, Colombo E, Mantegazza M, Scalmani P, Curia G, Avanzini G, Franceschetti S (2006) Layer-specific properties of the persistent sodium current in sensorimotor cortex. J Neurophysiol 95:3460-3468. CrossRef Medline

Bant JS, Raman IM (2010) Control of transient, resurgent, and persistent current by open-channel block by Na channel beta 4 in cultured cerebellar granule neurons. Proc Natl Acad Sci U S A 107:12357-12362. CrossRef Medline

Benda J, Herz AV (2003) A universal model for spike-frequency adaptation. Neural Comput 15:2523-2564. CrossRef Medline

Benda J, Longtin A, Maler L (2005) Spike-frequency adaptation separates transient communication signals from background oscillations. J Neurosci 25:2312-2321. CrossRef Medline

Brown DA, Griffith WH (1983) Persistent slow inward calcium current in voltage-clamped hippocampal neurones of the guinea-pig. J Physiol 337: 303-320. Medline

Callaway JC, Ross WN (1995) Frequency-dependent propagation of sodium action potentials in dendrites of hippocampal CA1 pyramidal neurons. J Neurophysiol 74:1395-1403. Medline

Cannon SC, Bean BP (2010) Sodium channels gone wild: resurgent current from neuronal and muscle channelopathies. J Clin Invest 120:80-83. CrossRef Medline

Castelli L, Biella G, Toselli M, Magistretti J (2007) Resurgent Na+ current in pyramidal neurones of rat perirhinal cortex: axonal location of channels and contribution to depolarizing drive during repetitive firing. J Physiol 582:1179-1193. CrossRef Medline

Chen S, Benninger F, Yaari Y (2014) Role of small conductance Ca2+activated $\mathrm{K}+$ channels in controlling CA1 pyramidal cell excitability. J Neurosci 34:8219-8230. CrossRef Medline

Chen Y, Yu FH, Surmeier DJ, Scheuer T, Catterall WA (2006) Neuromodulation of $\mathrm{Na}+$ channel slow inactivation via cAMP-dependent protein kinase and protein kinase C. Neuron 49:409-420. CrossRef Medline

Chen Y, Yu FH, Sharp EM, Beacham D, Scheuer T, Catterall WA (2008) Functional properties and differential neuromodulation of $\mathrm{Na}(\mathrm{v}) 1.6$ channels. Mol Cell Neurosci 38:607-615. CrossRef Medline

Chevaleyre V, Siegelbaum SA (2010) Strong CA2 pyramidal neuron synapses define a powerful disynaptic cortico-hippocampal loop. Neuron 66:560-572. CrossRef Medline

Colbert CM, Magee JC, Hoffman DA, Johnston D (1997) Slow recovery from inactivation of $\mathrm{Na}+$ channels underlies the activity-dependent attenuation of dendritic action potentials in hippocampal CA1 pyramidal neurons. J Neurosci 17:6512-6521. Medline

Dover K, Solinas S, D’Angelo E, Goldfarb M (2010) Long-term inactivation particle for voltage-gated sodium channels. J Physiol 588:3695-3711. CrossRef Medline

Eaholtz G, Colvin A, Leonard D, Taylor C, Catterall WA (1999) Block of brain sodium channels by peptide mimetics of the isoleucine, phenylalanine, and methionine (IFM) motif from the inactivation gate. J Gen Physiol 113:279-294. CrossRef Medline

Faber ES, Sah P (2002) Physiological role of calcium-activated potassium currents in the rat lateral amygdala. J Neurosci 22:1618-1628. Medline

Fleidervish IA, Friedman A, Gutnick MJ (1996) Slow inactivation of $\mathrm{Na}+$ channels current and slow cumulative spike adaptation in mouse and guinea-pig neocortical neurons in slices. J Physiol 493:83-97. Medline

Goetz R, Dover K, Laezza F, Shtraizent N, Tchetchik D, Huang X, Eliseenkova AV, Xu CF, Neubert TA, Ornitz DM, Goldfarb M, Mohammadi M (2009) Crystal structure of a fibroblast growth factor homologous factor (FHF) defines a conserved surface on FHFs for binding and modulation of voltage-gated sodium channels. J Biol Chem 284:17883-17896. CrossRef Medline

Goldfarb M, Schoorlemmer J, Williams A, Diwakar S, Wang Q, Huang X, Giza J, Tchetchik D, Kelley K, Vega A, Matthews G, Rossi P, Ornitz DM, D'Angelo E (2007) Fibroblast growth factor homologous factors control neuronal excitability through modulation of voltage-gated sodium channels. Neuron 55:449-463. CrossRef Medline
Gonoi T, Hille B (1987) Gating of Na channels. Inactivation modifiers discriminate among models. J Gen Physiol 89:253-274. CrossRef Medline

Grieco TM, Malhotra JD, Chen C, Isom LL, Raman IM (2005) Openchannel block by the cytoplasmic tail of sodium channel beta4 as a mechanism for resurgent sodium current. Neuron 45:233-244. CrossRef Medline

Gupta A, Wang Y, Markram H (2000) Organizing principles for a diversity of GABAergic interneurons and synapses in the neocortex. Science 287: 273-278. CrossRef Medline

Hartung H, Feldman B, Lovec H, Coulier F, Birnbaum D, Goldfarb M (1997) Murine FGF-12 and FGF-13: expression in embryonic nervous system, connective tissue and heart. Mech Dev 64:31-39. CrossRef Medline

Jung HY, Mickus T, Spruston N (1997) Prolonged sodium channel inactivation contributes to dendritic action potential attenuation in hippocampal pyramidal neurons. J Neurosci 17:6639-6646. Medline

Khaliq ZM, Gouwens NW, Raman IM (2003) The contribution of resurgent sodium current to high-frequency firing in Purkinje neurons: an experimental and modeling study. J Neurosci 23:4899-4912. Medline

Laezza F, Lampert A, Kozel MA, Gerber BR, Rush AM, Nerbonne JM, Waxman SG, Dib-Hajj SD, Ornitz DM (2009) FGF14 N-terminal splice variants differentially modulate Nav1.2 and Navl.6-encoded sodium channels. Mol Cell Neurosci 42:90-101. CrossRef Medline

Lou JY, Laezza F, Gerber BR, Xiao M, Yamada KA, Hartmann H, Craig AM, Nerbonne JM, Ornitz DM (2005) Fibroblast growth factor 14 is an intracellular modulator of voltage-gated sodium channels. J Physiol 569: 179-193. CrossRef Medline

Martina M, Jonas P (1997) Functional differences in Na+ channel gating between fast-spiking interneurones and principal neurones of rat hippocampus. J Physiol 505:593-603. Medline

Mickus T, Jung Hy, Spruston N (1999) Properties of slow, cumulative sodium channel slow inactivation in rat hippocampal CAl pyramidal neurons. Biophys J 76:846-860. CrossRef Medline

Miles GB, Dai Y, Brownstone RM (2005) Mechanisms underlying the early phase of spike frequency adaptation in mouse spinal motoneurones. J Physiol 566:519-532. CrossRef Medline

Milescu LS, Yamanishi T, Ptak K, Smith JC (2010) Kinetic properties and functional dynamics of sodium channels during repetitive spiking in a slow pacemaker neuron. J Neurosci 30:12113-12127. CrossRef Medline

Moyer JR Jr, Thompson LT, Black JP, Disterhoft JF (1992) Nimodipine increases excitability of rabbit CAl pyramidal neurons in an age- and concentration-dependent manner. J Neurophysiol 68:2100-2109. Medline

Moyer JR Jr, Power JM, Thompson LT, Disterhoft JF (2000) Increased excitability of aged rabbit CA1 neurons after trace eyeblink conditioning. J Neurosci 20:5476-5482. Medline

Munoz-Sanjuan I, Simandl BK, Fallon JF, Nathans J (1999) Expression of chicken fibroblast growth factor homologous factor (FHF)-1 and of differentially spliced isoforms of FHF-2 during development and involvement of FHF-2 in chicken limb development. Development 126:409-421. Medline

Otto JF, Yang Y, Frankel WN, White HS, Wilcox KS (2006) A spontaneous mutation involving Kcnq2 (Kv7.2) reduces M-current density and spike frequency adaptation in mouse CA1 neurons. J Neurosci 26:2053-2059. CrossRef Medline

Pedarzani P, Storm JF (1993) PKA mediates the effects of monoamine transmitters on the $\mathrm{K}+$ current underlying the slow frequency adaptation in hippocampal neurons. Neuron 11:1023-1035. CrossRef Medline

Peron S, Gabbiani F (2009) Spike frequency adaptation mediates looming stimulus selectivity in a collision-detecting neuron. Nat Neurosci 12:318 326. CrossRef Medline

Peters HC, Hu H, Pongs O, Storm JF, Isbrandt D (2005) Conditional transgenic suppression of $\mathrm{M}$ channels in mouse brain reveals functions in neuronal excitability, resonance and behavior. Nat Neurosci 8:51-60. CrossRef Medline

Platkiewicz J, Brette R (2011) Impact of fast sodium channel inactivation on spike threshold dynamics and synaptic integration. PLoS Comput Biol 7:e1001129. CrossRef Medline

Popovici C, Roubin R, Coulier F, Birnbaum D (2005) An evolutionary history of the FGF superfamily. Bioessays 27:849-857. CrossRef Medline

Raman IM, Bean BP (1997) Resurgent sodium current and action potential formation in dissociated cerebellar Purkinje neurons. J Neurosci 17: 4517-4526. Medline

Ran FA, Hsu PD, Lin CY, Gootenberg JS, Konermann S, Trevino AE, Scott DA, Inoue A, Matoba S, Zhang Y, Zhang F (2013) Double nicking by 
RNA-guided CRISPR Cas9 for enhanced genome editing specificity. Cell 154:1380-1389. CrossRef Medline

Rudy B (1981) Inactivation in Myxicola giant axons responsible for slow and accumulative adaptation phenomena. J Physiol 312:531-549. Medline

Rush AM, Wittmack EK, Tyrrell L, Black JA, Dib-Hajj SD, Waxman SG (2006) Differential modulation of sodium channel $\mathrm{Na}(\mathrm{v}) 1.6$ by two members of the fibroblast growth factor homologous factor 2 subfamily. Eur J Neurosci 23:2551-2562. CrossRef Medline

Sawczuk A, Powers RK, Binder MD (1995) Spike frequency adaptation studied in hypoglossal motoneurons of the rat. J Neurophysiol 73:17991810. Medline

Schoorlemmer J, Goldfarb M (2002) Fibroblast growth factor homologous factors and the islet brain-2 scaffold protein regulate a stress-activated protein kinase. J Biol Chem 277:49111-49119. CrossRef Medline

Shakkottai VG, Xiao M, Xu L, Wong M, Nerbonne JM, Ornitz DM, Yamada KA (2009) FGF14 regulates the intrinsic excitability of cerebellar Purkinje neurons. Neurobiol Dis 33:81-88. CrossRef Medline

Silva JR, Goldstein SA (2013a) Voltage-sensor movements describe slow inactivation of voltage-gated sodium channels I: wild-type skeletal muscle $\mathrm{Na}(\mathrm{V})$ 1.4. J Gen Physiol 141:309-321. CrossRef Medline

Silva JR, Goldstein SA (2013b) Voltage-sensor movements describe slow inactivation of voltage-gated sodium channels II: a periodic paralysis mutation in $\mathrm{Na}(\mathrm{V}) 1.4$ (L689I). J Gen Physiol 141:323-334. CrossRef Medline

Smallwood PM, Munoz-Sanjuan I, Tong P, Macke JP, Hendry SH, Gilbert DJ, Copeland NG, Jenkins NA, Nathans J (1996) Fibroblast growth factor (FGF) homologous factors: new members of the FGF family implicated in nervous system development. Proc Natl Acad Sci U S A 93:9850-9857. CrossRef Medline

Theile JW, Jarecki BW, Piekarz AD, Cummins TR (2011) Nav1.7 mutations associated with paroxysmal extreme pain disorder, but not erythromelalgia, enhance Navbeta4 peptide-mediated resurgent sodium currents. J Physiol 589:597-608. CrossRef Medline

Thompson SM, Masukawa LM, Prince DA (1985) Temperature dependence of intrinsic membrane properties and synaptic potentials in hippocampal CA1 neurons in vitro. J Neurosci 5:817-824. Medline

Tombaugh GC, Rowe WB, Rose GM (2005) The slow afterhyperpolariza- tion in hippocampal CA1 neurons covaries with spatial learning ability in aged Fisher 344 rats. J Neurosci 25:2609-2616. CrossRef Medline

Ulbricht W (2005) Sodium channel inactivation: molecular determinants and modulation. Physiol Rev 85:1271-1301. CrossRef Medline

Wang C, Chung BC, Yan H, Lee SY, Pitt GS (2012) Crystal structure of the ternary complex of a NaV C-terminal domain, a fibroblast growth factor homologous factor, and calmodulin. Structure 20:1167-1176. CrossRef Medline

Wang GK, Edrich T, Wang SY (2006) Time-dependent block and resurgent tail currents induced by mouse beta4(154-167) peptide in cardiac $\mathrm{Na}+$ channels. J Gen Physiol 127:277-289. CrossRef Medline

Wang H, Yang H, Shivalila CS, Dawlaty MM, Cheng AW, Zhang F, Jaenisch R (2013) One-step generation of mice carrying mutations in multiple genes by CRISPR/Cas-mediated genomic engineering. Cell 153:910-918. CrossRef Medline

Wang Q, McEwen DG, Ornitz DM (2000) Subcellular and developmental expression of alternatively spliced forms of fibroblast growth factor 14 Mech Dev 90:283-287. CrossRef Medline

Wang Y, Toledo-Rodriguez M, Gupta A, Wu C, Silberberg G, Luo J, Markram H (2004) Anatomical, physiological and molecular properties of Martinotti cells in the somatosensory cortex of the juvenile rat. J Physiol 561: 65-90. CrossRef Medline

West JW, Patton DE, Scheuer T, Wang Y, Goldin AL, Catterall WA (1992) A cluster of hydrophobic amino acid residues required for fast $\mathrm{Na}+$ channel inactivation. Proc Natl Acad Sci U S A 89:10910-10914. CrossRef Medline

Wozniak DF, Xiao M, Xu L, Yamada KA, Ornitz DM (2007) Impaired spatial learning and defective theta burst induced LTP in mice lacking fibroblast growth factor 14. Neurobiol Dis 26:14-26. CrossRef Medline

Wozny C, Williams SR (2011) Specificity of synaptic connectivity between layer 1 inhibitory interneurons and layer $2 / 3$ pyramidal neurons in rat neocortex. Cereb Cortex 21:1818-1826. CrossRef Medline

Xiao M, Bosch MK, Nerbonne JM, Ornitz DM (2013) FGF14 localization and organization of the axon initial segment. Mol Cell Neurosci 56:393403. CrossRef Medline

Yan H, Pablo JL, Pitt GS (2013) FGF14 regulates presynaptic Ca2 + channels and synaptic transmission. Cell Rep 4:66-75. CrossRef Medline 